\title{
Pore morphology and temperature dependence of gas transport properties of silica membranes derived from oxidative thermolysis of polydimethylsiloxane
}

Jason Adams ${ }^{\mathrm{a}}$ (Jasonadams110@gmail.com), Neha Bighane ${ }^{\mathrm{a}}$ (Nbighane3@ gmail.com), William J. Koros ${ }^{\mathrm{a}}(\text { Wjk@ chbe.gatech.edu })^{*}$

${ }^{\text {a }}$ School of Chemical \& Biomolecular Engineering, Georgia Institute of Technology, 311 Ferst Drive, Atlanta, GA 30332-0100, United States

* Corresponding author

\begin{abstract}
Transport properties of silica membranes derived from the oxidative thermolysis of crosslinked polydimethylsiloxane (PDMS) were studied between $35^{\circ} \mathrm{C}-100^{\circ} \mathrm{C}$. Changes in pore morphology and transport properties were investigated for varying thermolysis and crosslinking treatments. Permeation and pressure-decay sorption measurements were made for $\mathrm{CO}_{2}, \mathrm{H}_{2}, \mathrm{He}, \mathrm{O}_{2}, \mathrm{~N}_{2}$, and $\mathrm{CH}_{4}$. Physisorption data for $\mathrm{CO}_{2}$ and $\mathrm{N}_{2}$ were also analyzed to characterize the pore size distributions of these materials. The activation energies of permeation and diffusion were measured along with the enthalpies of sorption to compare the effects of varying fabrication methods. Titania crosslinked precursors showed a decrease in sorption capacity compared to the non-titania silicas, but all samples showed similar enthalpies of sorption. Regular and extendedthermolysis heat treated silica showed similar permeabilities and diffusion coefficients, but the heat treated silicas showed an average increase of $2.3 \mathrm{~kJ} / \mathrm{mol}$ in their activation energies of permeation. The permeation, sorption, and diffusion selectivities of various gas pairs were compared. The silica showed high sorption selectivity in gas pairs with large differences in critical temperature, but showed low diffusion selectivity due to low entropic selectivity. Overall, the PDMS-derived silicas show promise, but require further tuning to improve the entropic selectivity of penetrants.
\end{abstract}

\section{Keywords}

Silica membranes; Polysiloxanes; Entropic selectivity; Temperature dependence; Gas separations

\section{Introduction}

In 2011, 159 million tonnes of ammonia was produced globally through the Haber-Bosch process with an expected $2.4 \%$ growth per year [1]. This output is directly dependent on the production of hydrogen. Hydrogen is produced from steam reforming methane through the water gas shift (WGS) reaction, which produces $95 \%$ of global hydrogen but requires $\mathrm{H}_{2} / \mathrm{CO}_{2}$ separations [2]. Presently, $\mathrm{H}_{2} / \mathrm{CO}_{2}$ separations are dominated by pressure swing adsorption and energy intensive cryogenic distillation, but membrane separations may offer a lower energy cost than cryogenic distillation [3]. Metal membranes, such as palladium, currently dominate $\mathrm{H}_{2} / \mathrm{CO}_{2}$ membrane-based separations in the water gas shift (WGS) reaction, but silica membranes have potential in this field [4]. 
Silica membranes are attractive for high temperature gas separations due to more robust thermal stability compared to traditional polymeric membranes [5]. Similarly, silica membranes can exceed the productivity-selectivity upper limit seen in polymeric membranes [6] and [7]. While silica membranes tend to degrade in highly hydrothermal conditions, hydrophobic silicas are competitive with palladium alloy membranes, which also degrade in the presence of the WGS reaction [4], [8], and [9]. Silica is normally hydrophilic and condensation of micropores is reported under hydrothermal conditions, but silica can be made hydrophobic by eliminating surface hydroxyl groups by tuning the silica fabrication process [8], [10], and [11].

Silica membranes are typically fabricated by chemical vapor deposition (CVD) or the sol-gel method [12]. CVD fabrication often involves the deposition of tetraethylorthosilicate (TEOS) onto a support material at temperatures between $200-700^{\circ} \mathrm{C}$ [13]. Sol gel fabrication typically involves dip coating a support material into a sol precursor and calcining the membrane between $250-600^{\circ} \mathrm{C}$ [14]. Both of these methods involve high cost support materials, and an alternative method of thermally oxidizing polysiloxane rubbers may be more economical [12] and [15]. Work by Bighane and Koros explored the effects of thermolyzing low-cost cross-linked PDMS to produce hydrophobic silica membranes with performances similar to other silicas [7].

In order to better understand the transport properties, pore structure, and temperature dependence of these silica materials, it is useful to study their activation energy of permeation and enthalpy of sorption. Considerable research has focused on the permeation and sorption energetics of silica materials derived from both CVD and sol-gel methods, but little work has been done for PDMS-derived silica materials [16], [17], [18], [19], [20], [21], and [22]. In order to successfully implement PDMS-derived silica technology, it is important to understand how their transport properties change with temperature and varying fabrication methods. Further, understanding the energetics of these PDMS-derived silicas provides insight into their pore structure and possibly can help in the development of higher-performing silica materials.

The current work presents a detailed study of the permeation and sorption energetic properties of such PDMS-derived silicas. Specifically the permeability and pressure-decay sorption of these materials were measured at varying temperatures for $\mathrm{CO}_{2}, \mathrm{H}_{2}, \mathrm{He}, \mathrm{O}_{2}, \mathrm{~N}_{2}$, and $\mathrm{CH}_{4}$. The silica materials were produced with varying thermolysis cycles and metal cross-linking agents to investigate the effects on the silica energetic properties. The results of these studies and further material characterization allows for a better understanding of the pore structure in these PDMSderived silicas [23].

\section{Theory and background}

\subsection{Transport in molecular sieving silica membranes}

Gas transport in selective microporous silica follows the sorption-diffusion model, where gas molecules first adsorb on the high-pressure interface of a membrane. Sorbed molecules then diffuse through the membrane under a chemical potential gradient and desorb at the downstream low-pressure face. In this model, the pressure and thickness normalized throughput or permeability $\left(P_{A}\right)$ can be represented as the product of the diffusion $\left(D_{A}\right)$ and sorption $\left(\mathbb{S}_{A}\right)$ coefficients [24]. The permeability can also be measured as the molecular flux $\left(J_{A}\right)$ through the 
membrane thickness $(l)$ under a constant partial pressure difference $\left(\Delta p_{A}\right)$ as shown in Eq. (1) below with the standard unit of permeability [25].

$$
\begin{gathered}
P_{A}=D_{A} * \mathbb{S}_{A}=\frac{J_{A^{* l}}}{\Delta p_{A}} \\
1 \text { barrer }=10^{-10} \frac{\mathrm{c} c_{S T P} \cdot \mathrm{cm}}{\mathrm{cm}^{2} \cdot \mathrm{s} \cdot \mathrm{cmHg}}
\end{gathered}
$$

The diffusion coefficient characterizes the rate at which gas molecules make jumps through a selective membrane matrix. The sorption coefficient $\left(\mathbb{S}_{A}\right)$ describes the equilibrium concentration $\left(C_{A}\right)$ of gas adsorbed at a given partial pressure $\left(p_{A}\right)$ as shown in Eq. (2).

$$
\mathbb{S}_{A}=\frac{C_{A}}{p_{A}}
$$

Note the symbol $\mathbb{S}_{A}$ used for the sorption coefficient to distinguish it from the entropy of gas $\mathrm{A}$ $\left(\mathrm{S}_{A}\right)$ discussed below. The sorption coefficient depends on gas condensability and interaction with the membrane material. For a membrane with a finite number of sorption sites and rigid saturatable capacity, like silicas, the concentration of adsorbed gas can be described by the Langmuir model shown in Eq. (3).

$$
C_{A}=\frac{C^{\prime} b_{A} p_{A}}{1+b_{A} p_{A}}
$$

This model assumes that there is a maximum saturation capacity $\left(C_{A}^{\prime}\right)$ that depends on the number of sorption sites in the material, which increases with the total pore volume. The relative loading of the sorption sites as a function of pressure depends on the Langmuir affinity constant $\left(b_{A}\right)$, which is a measure of how strongly the gas is attracted to the sorption sites in a material [26], [27], and [28].

Pore sizes in silica materials vary significantly. The smallest pores $(<4 \AA)$, referred to as critical molecular sieving ultramicropores, may restrict the rotational and vibrational degrees of freedom of diffusing molecules and entropically select gas molecules based on their shape and size. Similarly, these critical ultramicropores exploit differences in molecular kinetic diameter and select gases based on the differences of their activation energies of diffusion. Finally, as noted above, gases are selectively adsorbed into these membranes based on their condensability and interactions with functional groups in these materials [29], [30], and [31]. The combination of these three selectivities leads to the overall permselectivity $\left(\alpha_{A / B}\right)$ of the membrane, which can be characterized as the ratio of the permeability of both gases as shown in Eq. (4).

$$
\alpha_{A / B}=\frac{P_{A}}{P_{B}}=\frac{D_{A}}{D_{B}} * \frac{\mathbb{S}_{A}}{\mathbb{S}_{B}}
$$

\subsection{Temperature dependence of transport properties}

Transport properties of penetrants in membranes show a temperature dependence. The activation energies of permeation and diffusion follow an Arrhenius relationship in Eqs. (5) and (6), respectively, while the enthalpy of sorption follows a van't Hoff relationship in Eq. (7) [32] and [33]. 


$$
\begin{aligned}
& P_{A}=P_{0, A} \exp \left(\frac{-E_{P, A}}{R T}\right) \\
& D_{A}=D_{0, A} \exp \left(\frac{-E_{D, A}}{R T}\right) \\
& \mathbb{S}_{A}=\mathbb{S}_{0, A} \exp \left(\frac{-\Delta H_{S, A}}{R T}\right)
\end{aligned}
$$

Where $P_{0, A}, D_{0, A}$, and $\mathbb{S}_{0, A}$ are the pre-exponential factors of permeation, diffusion, and sorption and $E_{P, A}, E_{D, A}$, and $\Delta H_{S, A}$ are the respective activation energy of permeation, activation energy of diffusion, and enthalpy of sorption. Further, rearrangement of Eqs. (5), (6), and (7) yield Eqs. (8) and (9). The uncertainty of diffusion parameters can be calculated from the uncertainty of permeation and sorption data through the propagation of error formulas reported by $\mathrm{Ku}$ [34].

$$
\begin{aligned}
& P_{0, A}=D_{0, A} * \mathbb{S}_{0, A} \\
& E_{P, A}=E_{D, A}+\Delta H_{S, A}
\end{aligned}
$$

The Langmuir affinity also shows a temperature dependence controlled by the enthalpy of sorption and the pre-exponential factor of the Langmuir affinity $\left(b_{0, A}\right)$ in Eq. (10). The preexponetial factor depends on the entropy of a gas existing in a sorbed state $\left(S_{s o r b, A}\right)$ and a free state $\left(S_{g a s, A}\right)$ as shown in Eq. (11) [32]. The significance of this energetic relationship is expanded upon in the appendix.

$$
\begin{aligned}
& b_{A}=b_{0, A} \exp \left(\frac{-\Delta H_{S, A}}{R T}\right) \\
& b_{0, A}=\exp \left(\frac{S_{\text {Sorb }, A}-S_{\text {gas }, A}}{R}\right)
\end{aligned}
$$

The energetic properties that control the temperature dependence of gas transport rely on a combination of the membrane's material properties and the penetrant properties. Specifically, the

\begin{tabular}{|c|c|c|c|}
\hline Penetrant gas & Kinetic diameter $(\AA)$ & Critical temperature $(\mathrm{K})$ & $\begin{array}{l}\text { Enthalpy of condensation } \\
(\mathrm{kJ} / \mathrm{mol}) \text { at boiling point }\end{array}$ \\
\hline $\mathrm{CO}_{2}$ & 3.30 & 304 & -16.5 \\
\hline $\mathrm{CH}_{4}$ & 3.80 & 191 & -8.2 \\
\hline $\mathrm{N}_{2}$ & 3.64 & 126 & -5.6 \\
\hline $\mathrm{O}_{2}$ & 3.46 & 155 & -6.8 \\
\hline $\mathrm{He}$ & 2.60 & 5.2 & -0.08 \\
\hline $\mathrm{H}_{2}$ & 2.89 & 33.2 & -0.46 \\
\hline
\end{tabular}
activation energy of diffusion $\left(E_{D, A}\right)$ depends on the gas kinetic diameter, while the enthalpy of sorption depends on the gas critical temperature, enthalpy of condensation, and interactions with the membrane matrix. These parameters have been tabulated in Table 1 for the gases used in this study [33].

Table 1. Kinetic diameters, critical temperatures, and enthalpies of condensation for the penetrant gases studied [35] and [36]. 


\subsection{Energetic and entropic considerations of diffusion and sorption}

The temperature dependence of molecules permeating through a rigid membrane can reveal how penetrant gases shift between sorbed and diffusing states during passage through the membrane. Sorption in the membrane media can be viewed like a phase change where the free gas state condenses into a sorbed state on the pore walls or within the pores of the membrane. In contrast, diffusion through the pores of a rigid membrane can be viewed as a series of activated jumps through the critical ultramicropores of the membrane media. The pre-exponential factor in Eq. (6) can be effectively interpreted in terms of transition state theory as shown in Eq. (12) below [37], [38], and [39].

$$
D_{0, A}=e \lambda^{2} \frac{k T}{h} \exp \left(\frac{S_{D, A}^{\ddagger}}{R}\right)
$$

Where $\lambda$ is the average diffusive jump length, $k$ is Boltzmann's constant, $h$ is Planck's constant, and $S_{D, A}^{\ddagger}$ is the activation entropy of diffusion.

Since the jump length between rigid pores is the same, the diffusion pre-exponential factor can be used to quantitatively describe both the energetic and entropic diffusion selectivity of different gases in a membrane structure. These diffusion selectivities can be calculated by combining Eqs. (4), (6), and (12) to yield Eq. (13) below [40] and [41].

$$
\begin{gathered}
\frac{D_{A}}{D_{B}}=\frac{D_{0, A}}{D_{0, B}} \exp \left(-\frac{E_{D_{A}}-E_{D_{B}}}{R T}\right)= \\
\exp \left(\frac{S_{D, A}^{\ddagger}-S_{D, B}^{\ddagger}}{R}\right) \exp \left(-\frac{E_{D_{A}}-E_{D_{B}}}{R T}\right)=\underbrace{\exp \left(\frac{S_{D, A, B}^{\ddagger}}{R}\right)} \underbrace{\exp \left(-\frac{\Delta E_{D_{A, B}}}{R T}\right)}
\end{gathered}
$$

Entropic Selectivity Energetic Selectivity

Transition state theory can also describe the overall diffusion as Eq. (14)

$$
D_{A}=\lambda^{2} \frac{k T}{h} \frac{F^{\ddagger}}{F} \exp \left(-\frac{E_{D_{A}}}{R T}\right)
$$

where $F$ is the partition function describing a gas molecule in a ground state within a micropore while $F^{\ddagger}$ is the partition function for a molecule in the transition state while passing through a critical ultramicropore. Both partition functions can be expressed as the product of their translational $\left(F_{\text {trans }}\right)$, rotational $\left(F_{\text {rot }}\right)$, and vibrational $\left(F_{v i b}\right)$ contributions in Eqs. $(15)$ and $(16)$.

$$
\begin{aligned}
& F=F_{\text {trans }} F_{\text {rot }} F_{\text {vib }} \\
& F^{\ddagger}=F_{\text {trans }}^{\ddagger} F_{\text {rot }}^{\ddagger} F^{\ddagger}{ }_{\text {vib }}
\end{aligned}
$$

During the transition state in the critical ultramicropore, the geometry of the pore limits the degrees of freedom of the diffusing molecules. Different gases have different geometries and may experience different limitations in their degrees of freedom. This difference may result in an entropic selectivity between the gases, which can be described by combining Eqs. (13) and (14) to Eq. (17) [42]. 


$$
\frac{D_{0, A}}{D_{0, B}}=\exp \left(\frac{\Delta S_{D_{A, B}}}{R}\right)=\frac{\left(F^{\ddagger} / F\right)_{A}}{\left(F^{\ddagger} / F\right)_{B}}
$$

By exploiting the geometry of the critical ultramicropores, in principle, it is possible to create materials with high entropic selectivies between gas pairs, which are optimal for achieving high permselectivities.

\section{Experimental}

\subsection{Polymer precursor preparation}

As has been discussed by Bighane, solution casting and crosslinking was used in the current study to fabricate PDMS dense films [7] and [43]. Commercially available silanol-terminated PDMS purchased from Gelest Inc. was used in this work. The PDMS was dissolved in anhydrous n-heptane to form an $11 \mathrm{wt} \%$ polymer solution and then mixed at $3000 \mathrm{rpm}$ on a digital vortex mixer for four minutes. Then a crosslinking agent of either tetraethoxysilane (TEOS) or titanium ethoxide was mixed in at a 1:5 mass ratio to the PDMS. Afterwards, 12-15 mg of titanium-2-ethylhexoxide and di-n-butylacetoxtin catalysts were added per gram of PDMS. This final solution was then further mixed at $3000 \mathrm{rpm}$ for one minute.

The solution was then immediately cast into a circular Teflon dish in a glove bag filled with an $\mathrm{N}_{2}$ atmosphere. Petri dishes of water were then placed in the glove bag, and the relative humidity was maintained between $50-70 \%$ for 24 hours. This humidity accelerates the condensation cure chemistry, which is discussed in detail in Bighane's work [7]. After the films equilibrated for 24 hours, they were left to dry under vacuum at $100^{\circ} \mathrm{C}$ for 12 hours followed by $120^{\circ} \mathrm{C}$ for 36 hours. After cooling, the PDMS precursor was cut by a $1 / 2$ in. diameter die-cutter for use in the oxidative thermolysis.

\subsection{Silica dense film formation}

The PDMS disks were then placed on a fine stainless-steel wire mesh, which allowed for roughly equal rates of oxidation on both sides of the polymer. This mesh was then loaded into a quartz tube, which was within a single-zone thermcraft oven [7], [43], and [44]. The tube was then purged with $\mathrm{O}_{2}$ flowing between $30-50 \mathrm{~mL} / \mathrm{min}$, which was regulated with a mass flow controller. The oven was allowed to purge for several hours before initiating the thermolysis protocol. A detailed description of this set up is shown in Fig. 1 below.

Three separate thermolysis protocols were used for the (i) regular, (ii) heat treated, and (iii) titania-crosslinked silicas, which are shown in Fig. 2. The only significant difference between the regular and heat treated silica is the additional 90 minute temperature soak at $377^{\circ} \mathrm{C}$. The titaniacrosslinked silica used a significantly different protocol with a much slower ramp time and higher temperature soak to achieve optimum properties. All of these protocols are based on work completed by Bighane, which include a detailed mechanistic explanation of this controlled oxidation [43], [44], and [45]. 


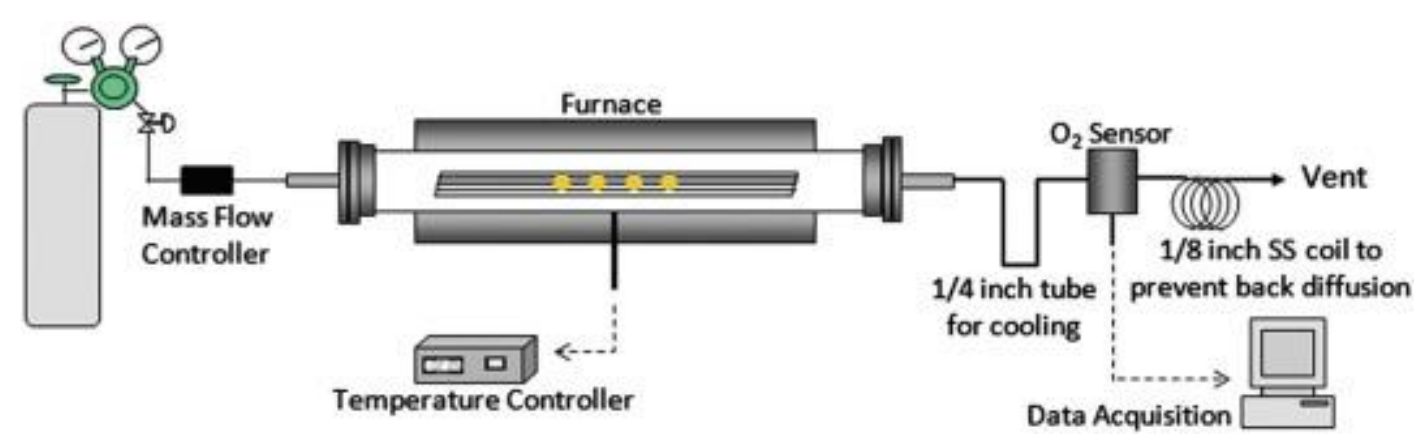

Fig. 1. A schematic of the single zone thermolysis system used for membrane fabrication in this study [46].

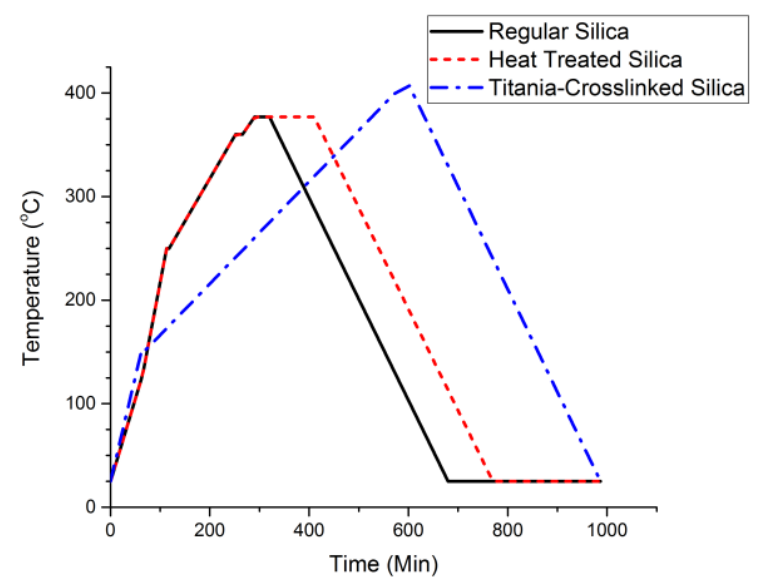

Fig. 2. Thermolysis heating protocols showing a gradual ramping to a max soak temperature $\left(377^{\circ} \mathrm{C}\right.$ or $\left.407^{\circ} \mathrm{C}\right)$ followed by a controlled gradual cooling back to room temperature.

\subsection{Pressure decay sorption measurements}

Silica dense film samples were weighed and loaded into constant-volume pressure-decay sorption systems using techniques reported by Koros et al. [47]. Each system was allowed to equilibrate at an oil bath temperature of either 35,50 , or $70^{\circ} \mathrm{C}$ under vacuum for at least 24 hours to fully desorb gas from the samples within their sorption systems. When the testing was ready to start, the LabVIEW pressure readings were zeroed and the sample valves were closed. The reservoirs were filled with the test gas and brought to the necessary pressures to provide the desired pressure after opening the sample valves. Then, the reservoir valves were closed and the gas was allowed to equilibrate for 10 minutes. Afterwards, the testing began and continued for another 10 minutes to establish a baseline initial pressure. Then, the sample valve was temporarily opened to pressurize the sample. Pressure readings were continuously recorded until equilibrium was achieved. In this study, 3-5 sorption samples were tested per material for each tested gas. 


\subsection{Permeation measurements}

Silica dense film samples were masked and mounted in permeation cells using Kapton® tape and the tape/membrane interface was sealed using Duralco® 4525 epoxy. The details of this masking procedure have been described in previous works reported by Moore et al. [48]. These permeation cells were then placed into a high temperature constant-volume variable-pressure system with a similar design to the prior works of Pye et al. [49] and [50]. The epoxy on this permeation cell was allowed to dry for 4 hours in the permeation box before lightly pulling vacuum on the membrane to verify a good mounting seal. The system was then sealed and both the upstream and downstream were degassed for 24 hours.

The system was allowed to equilibrate at a temperature of either 35,70 , or $100^{\circ} \mathrm{C}$ in a vacuum for at least 4 hours. Afterwards, a leak rate was measured to ensure that any leaks were small (typically $<1 \%$ ) relative to the rate of gas permeation. The isolation valve was closed and the system would be pressurized to either 51.3 or 102.6 psia and allowed to equilibrate for 15 minutes. When the testing started, the upstream pressure was noted and downstream pressure readings were recorded through LabVIEW. The sample permeated until it reached steady state.

After testing was completed, the area of the exposed membrane was measured using ImageJ [51]. The samples were removed from the permeation cell and the membrane thickness would be measured with a digital micrometer. Finally the permeation cell was cleaned for further testing. In this study, 2-3 permeation samples were tested per material for each tested gas.

\subsection{Material characterization}

Silica dense film samples were characterized by Brunauer-Emmett-Teller (BET) physisorption, Fourier transform infrared spectroscopy (FTIR), and density column analysis. In the BET analysis, a Miromeritics ASAP 2020 was used to determine the pore volume and size distributions of silica samples. This was performed by dosing a sample with either $\mathrm{CO}_{2}$ or $\mathrm{N}_{2}$ between 0-1 bar and measuring the sorption of these gases. For this analysis, $\mathrm{CO}_{2}$ physisorption was performed with 100 pressure points at $0^{\circ} \mathrm{C}$ while $\mathrm{N}_{2}$ physisorption was performed with 14 pressure points at $-196^{\circ} \mathrm{C}$. For our instrument, $\mathrm{CO}_{2}$ physisorption measures the pore volume of pore widths between 4-9 $\AA$ while $\mathrm{N}_{2}$ physisorption measures pore widths greater than $11 \AA$. For FTIR, silica samples and their precursors were scanned to determine how dominant functional groups changed based on the fabrication process. Finally density gradient column analysis involved submerging samples in a liquid column of varying densities, and allowed for precise calculation of a sample's density. 


\section{Results and discussion}

\subsection{FTIR analysis of silica and PDMS precursor}

FTIR analysis was performed on both the TEOS crosslinked PDMS and titanium ethoxide crosslinked PDMS. The same analysis was then performed on these samples after undergoing thermolysis as shown in Fig. 3 below.
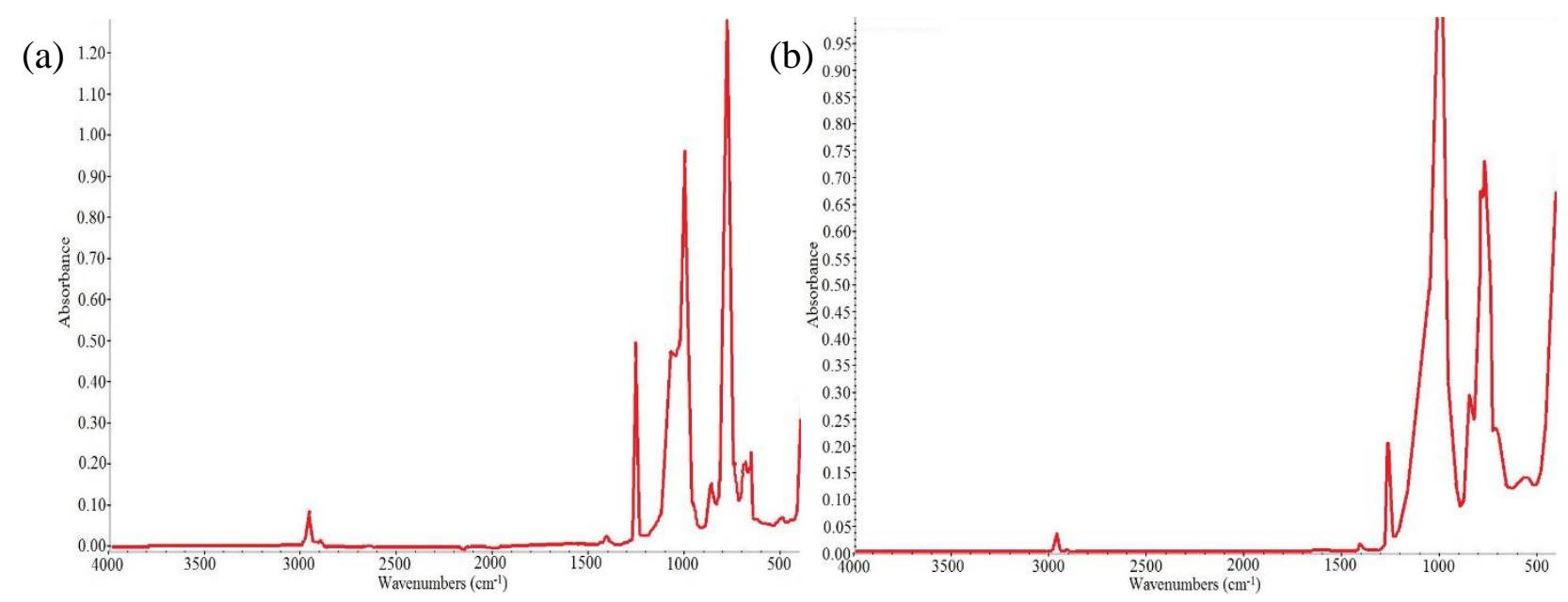

(c)
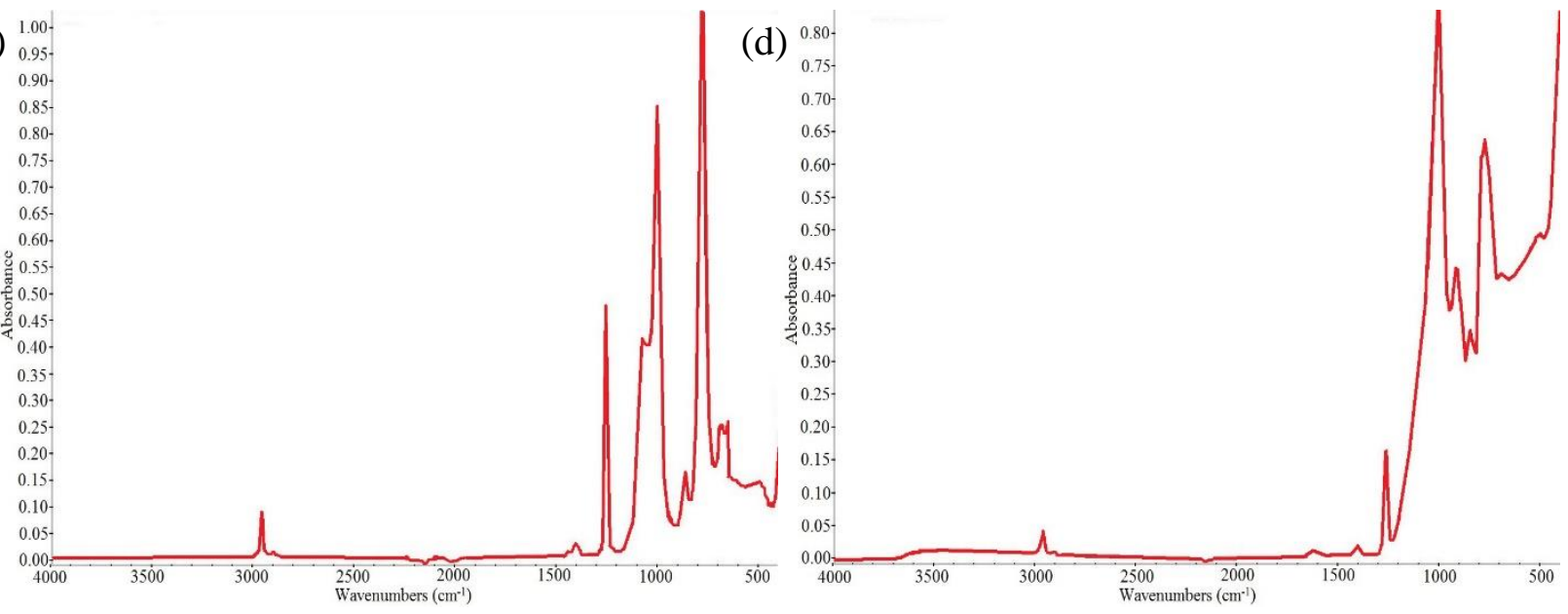

Fig. 3. The FTIR spectrum for the (a) TEOS crosslinked PDMS precursor, (b) oxidized PDMS precursor (c) Titanium Ethoxide crosslinked PDMS precursor, and (d) oxidized titaniacrosslinked PDMS precursor.

The TEOS and titanium ethoxide spectra both show a reduction in the $\mathrm{CH}_{3}$ symmetric deformation of $\mathrm{Si}-\mathrm{CH}_{3}$ at $1270 \mathrm{~cm}^{-1}$, while showing a significant increase in the amorphous silica broad shoulder at $1220 \mathrm{~cm}^{-1}$. Similarly both spectra show a reduction in the polysiloxane peak at $800 \mathrm{~cm}^{-1}$ and an increase in the Si-O-Si stretching vibrations between $1000-1130 \mathrm{~cm}^{-1}$. This indicates a reduction in methyl groups and increase of amorphous silica in the PDMS precursor after thermolysis. Specifically for the titanium ethoxide spectra, there was an increase in the Si- 
$\mathrm{O}$-Ti band at $925 \mathrm{~cm}^{-1}$ [52]. This result indicates that titanium is being integrated into the amorphous silica as methyl groups are removed during the oxidation. Overall these observations are consistent with results from Bighane et al. and indicate that a similar silica material was created. ${ }^{7}$ Other FTIR spectra were recorded to show the effects of longer temperature soaks, but the spectra did not show noticeable differences from the figure above. This indicates that this treatment had little effect on the functional groups within these materials.

\section{2. $\mathrm{N}_{2}$ and $\mathrm{CO}_{2}$ physisorption results}

The main transport properties of these silica materials are related to the pore size distributions and pore morphologies in these silicas. Moreover, $\mathrm{CO}_{2}$ and $\mathrm{N}_{2}$ physisorption data were analyzed in terms of density functional theory to generate plots of the differential pore volume in Fig. 4 below [53] and [54]. This analysis assumed a carbon slit geometry, but in any case these results can still be used to show trends and approximate the range and prominence of pores sizes in these materials.

(a)

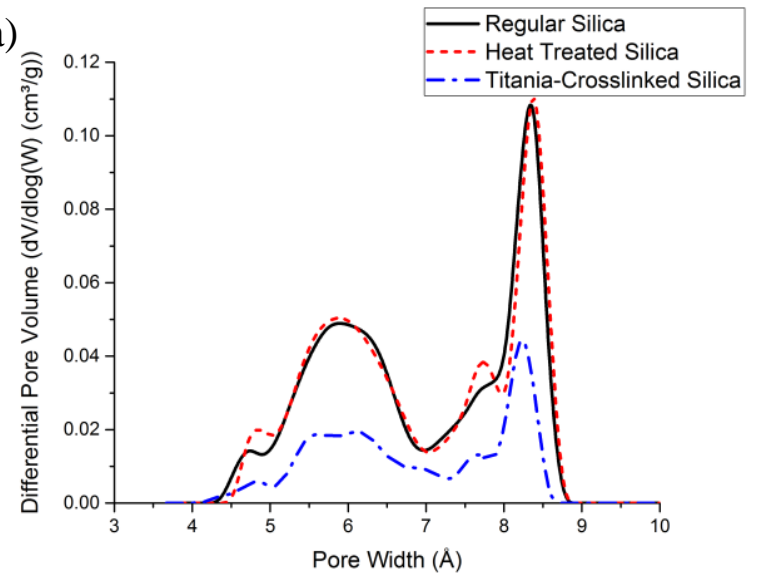

(b)

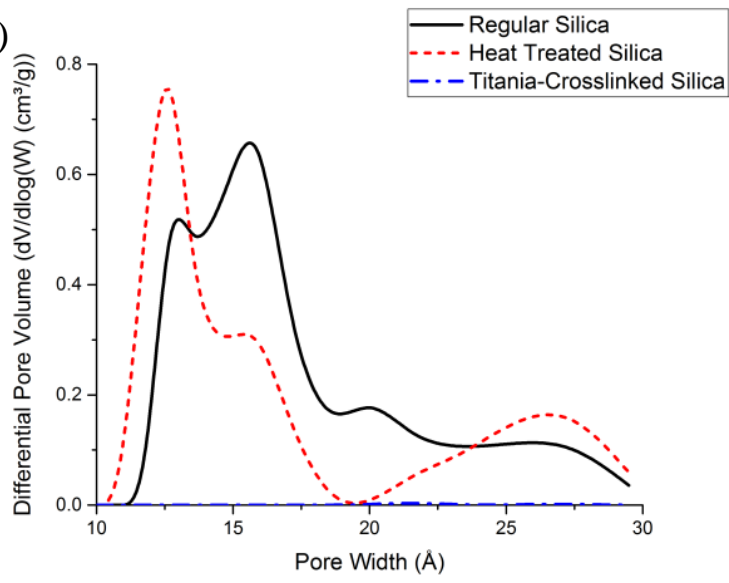

Fig. 4. Pore size distribution derived from (a) $\mathrm{CO}_{2}$ physisorption and (b) $\mathrm{N}_{2}$ physisorption data.

These data show a distribution of ultramicropores $(<7 \AA)$, micropores (7-20 $)$, and mesoporous (20-50 А). There may also be a population of critical ultramicropores that are smaller than $4 \AA$, which cannot be detected by either $\mathrm{CO}_{2}$ or $\mathrm{N}_{2}$ physisorption. Similarly, pores that lie within 9-11 $\AA$ cannot be detected by either method. Given these pore morphologies, the micropores and mesopores are expected to control the magnitude of gas diffusion and sorption capacity. However, this information says nothing about the raw diffusion selectivity, which is determined solely by the critical ultramicropores.

When comparing the $\mathrm{CO}_{2}$ physisorption results for the different silicas in Fig. 4, each material showed a similar pattern in their ultramicropore size distributions. The ultramicropore size distributions of the regular silica and heat treated silica were almost identical, while the titaniacrosslinked silica showed a significant reduction in magnitude of the differential pore volume. However, the similar patterns between each material indicates that heat treatment or titania crosslinking affects the ultramicropore volume, but not necessarily the ultramicropore geometry. 
The consistent ultramicropore geometry may indicate the presence of rigid siloxane ring structures, which have also been observed in CVD derived silica materials [21].

In contrast, the $\mathrm{N}_{2}$ physisorption results showed very different trends between the micropores and mesopores of these materials. Overall the silica and heat treated silica had very prominent pore size distributions, and the heat treated silica only showed a slight reduction in both pore surface area and volume. The most notable difference is that the pore size distribution has shifted in the heat treated silica compared to the regular silica, which may result from reorganization of the silica matrix due the increased densification observed in the heat-treated silica. The titaniacrosslinked silica showed a reduction in pore volume compared to the regular silica. It seems that the presence of the titania-crosslinker prevents or hinders the formation of these larger pores during the thermal oxidation process. It is also possible that the titania-crosslinker results in many pores located in the 9-11 ̊ range, which cannot be detected by either $\mathrm{CO}_{2}$ or $\mathrm{N}_{2}$ physisorption.

Both the regular silica and heat treated silica show similar trends and the data indicate that these materials should have very similar sorption capacities and large diffusion coefficients. In contrast, the titania-crosslinked silicas have much smaller pore volumes and average pore widths. This result indicates that the titania-crosslinked silica should have a less open structure with a smaller sorption capacity and diffusivity compared to the other silicas. The cumulative pore volumes and surface areas of each pore size distribution can be found in Table 2 below.

Table 2. Total pore volumes and surface areas calculated from both $\mathrm{CO}_{2}$ and $\mathrm{N}_{2}$ physisorption for regular, heat treated, and titania-crosslinked silica materials.

\begin{tabular}{|c|c|c|c|}
\hline \multirow[t]{2}{*}{ Silica Membranes: } & \multicolumn{3}{|c|}{$\mathrm{CO}_{2}$ and $\mathrm{N}_{2}$ Physisorption Data } \\
\hline & $\mathrm{CO}_{2}$ Physisorption (4-9 $\AA$ ) & $\mathrm{N}_{2}$ Physisorption $(>11 \AA)$ & Total \\
\hline & \multicolumn{3}{|l|}{ Pore volume $\left(\mathrm{cm}^{3} / \mathrm{g}\right)$} \\
\hline Regular Silica & 0.00973 & 0.115 & 0.125 \\
\hline Heat Treated Silica & 0.00991 & 0.100 & 0.110 \\
\hline Titania-Crosslinked Silica & 0.00384 & 0.00384 & 0.00768 \\
\hline \multicolumn{4}{|c|}{ Pore Surface Area $\left(\mathrm{m}^{2} / \mathrm{g}\right)$} \\
\hline Regular Silica & 29.9 & 144 & 173 \\
\hline Heat Treated Silica & 30.5 & 137 & 167 \\
\hline Titania-Crosslinked Silica & 11.9 & 0.264 & 12.2 \\
\hline
\end{tabular}

\subsection{Temperature dependence of gas permeation}

In this study, $\mathrm{CO}_{2}, \mathrm{CH}_{4}, \mathrm{~N}_{2}, \mathrm{O}_{2}, \mathrm{He}$, and $\mathrm{H}_{2}$ permeability data of silica derived from thermally oxidized PDMS were obtained at 50 and 100 psia and at temperatures of 35,70 , and $100^{\circ} \mathrm{C}$. Unfortunately, permeability measurements of the titania-crosslinked silicas could not be recorded due to extreme curling during the thermolysis process, which made membrane masking impractical. This feature clearly compromises such materials for practical membrane applications. 
Fig. 5 shows the temperature dependence of the permeability of the tested gas in the silica and heat-soaked silica. As stated by Eq. (9), the temperature dependence of gas permeability results from the sorption and diffusion temperature dependence. Gas adsorption generally decreases with temperature due to negative enthalpies of sorption, while diffusion generally increases with temperature due to positive activation energies of diffusion. Since many of the tested gases have similar magnitudes of these two energetic quantities, the energy of permeation of many tested gases can either be positive, negative, or near zero where $\mathrm{CO}_{2}<\mathrm{CH}_{4}<\mathrm{O}_{2}<\mathrm{N}_{2}<\mathrm{H}_{2}<\mathrm{He}$. Similarly there are no clear trends between the penetrants gases and their magnitudes of permeability due to the competing effects of sorption and diffusion coefficients. The activation energies of permeation in these silicas show similar trends to sol-gel derived silicas where $\mathrm{CO}_{2}<$ $\mathrm{CH}_{4}<\mathrm{O}_{2}<\mathrm{N}_{2}<\mathrm{H}_{2}<\mathrm{He}$. The notable difference is that the activation energy of permeation in silicas tested in this study are more positive than those derived from the sol gel method. ${ }^{22}$ Since the enthalpies of sorption are expected to be similar between these materials, this difference may come from a higher activation energy of diffusion in the silica used in this study.
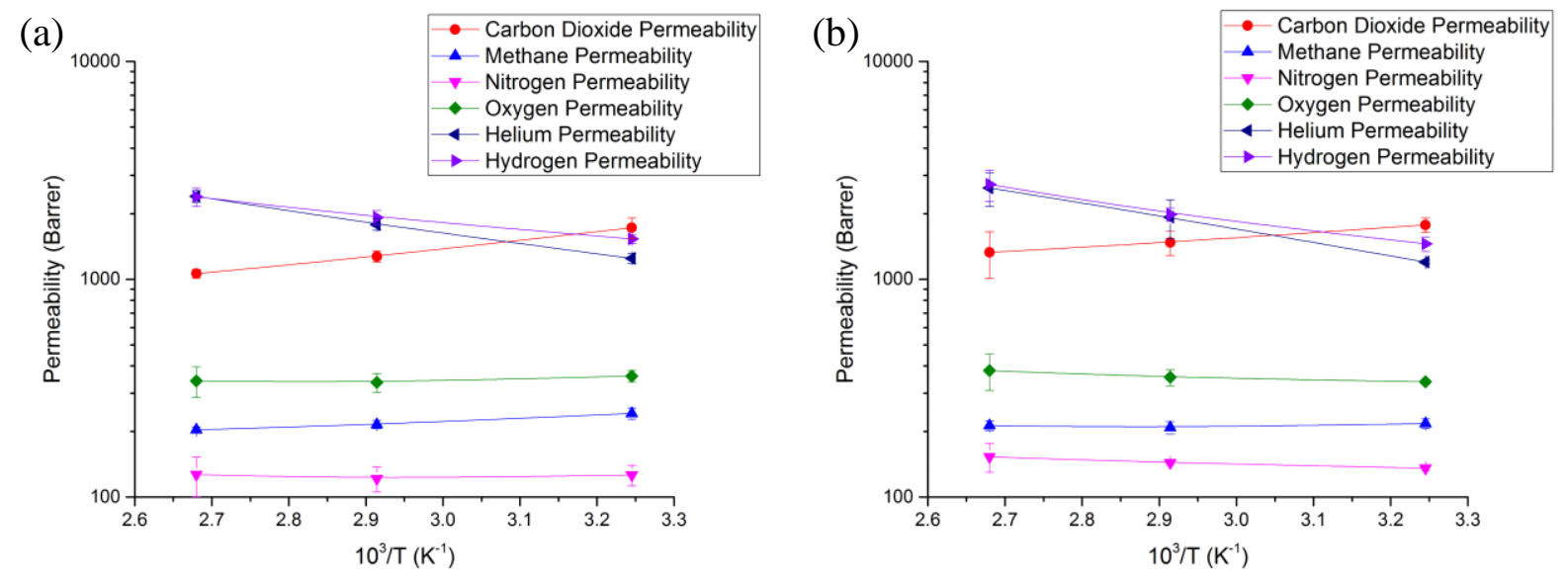

Fig. 5. Permeation temperature dependence of $\mathrm{CO}_{2}, \mathrm{CH}_{4}, \mathrm{~N}_{2}, \mathrm{O}_{2}, \mathrm{He}$, and $\mathrm{H}_{2}$ at 50 psia in (a) regular and (b) heat treated silica with error bars representing $95 \%$ confidence intervals.

Note that $\mathrm{CO}_{2}$ has a small kinetic diameter $(3.30 \AA)$ and is highly condensable compared to the other tested gases. The small kinetic diameter results in a small activation energy to diffuse through the critical ultramicropores, and the high condensability of $\mathrm{CO}_{2}$ and siloxane interactions in the silica results in a highly negative enthalpy of sorption and overall negative energy of permeation. This complex tradeoff between these energetic factors means that there is no clear trend between penetrant size and the activation energy of permeation, which is often seen in other membrane materials such as carbon molecular sieves (CMS) [55]. A detailed discussion of the temperature dependence of sorption and diffusion for varying penetrants will be presented in the later sections. 
Table 3. Activation energies and pre-exponential factors of permeation for $\mathrm{CO}_{2}, \mathrm{CH}_{4}, \mathrm{~N}_{2}, \mathrm{O}_{2}, \mathrm{He}$, and $\mathrm{H}_{2}$ at 50 psia in regular and heat treated silica between 35 to $100^{\circ} \mathrm{C}$ with $95 \%$ confidence intervals.

\begin{tabular}{|c|c|c|c|c|c|c|}
\hline \multirow[t]{2}{*}{ Silica Membranes: } & \multicolumn{6}{|c|}{ Permeation Energetics } \\
\hline & $\mathrm{CO}_{2}$ & $\mathrm{CH}_{4}$ & $\mathrm{~N}_{2}$ & $\mathrm{O}_{2}$ & $\mathrm{He}$ & $\mathrm{H}_{2}$ \\
\hline \multicolumn{7}{|c|}{$E_{P}(\mathrm{~kJ} / \mathrm{mol})$} \\
\hline Regular Silica & $-7.2 \pm 0.3$ & $-2.6 \pm 0.2$ & $-0.1 \pm 0.6$ & $-0.9 \pm 0.5$ & $9.6 \pm 0.2$ & $6.5 \pm 0.3$ \\
\hline Heat Treated Silica & $-4.4 \pm 0.6$ & $-0.4 \pm 0.2$ & $1.7 \pm 0.4$ & $1.6 \pm 0.5$ & $11.5 \pm 0.6$ & $9.1 \pm 0.5$ \\
\hline \multicolumn{7}{|c|}{$P_{0}\left(10^{3}\right.$ Barrer $)$} \\
\hline Regular Silica & $0.11 \pm 0.01$ & $0.09 \pm 0.01$ & $0.12 \pm 0.03$ & $0.25 \pm 0.07$ & $52.5 \pm 4.62$ & $190 \pm 2.14$ \\
\hline Heat Treated Silica & $0.32 \pm 0.07$ & $0.19 \pm 0.02$ & $0.26 \pm 0.03$ & $0.64 \pm 0.11$ & $105 \pm 22.8$ & $50.4 \pm 8.54$ \\
\hline
\end{tabular}

Table 3 above shows a tabulation of the activation energies of permeation and their respective pre-exponential factors for the various tested gases and silica materials. When comparing these materials, the heat soaked silica shows a universal increase in the activation energies of permeation and the pre-exponential factors. This increase in activation energy is probably due to a smaller average diameter in the critical ultramicropores. This difference increases the activation energy of diffusion while the enthalpy of sorption remains roughly constant. Further details of the effects of the critical ultramicropores on the activation energy of diffusion will be discussed in the diffusion section. The pre-exponential factors represent the permeability at an idealized infinite temperature described by Eq. (8). This permeability is dependent on a combination of the entropy to exist in sorbed and diffusing states. It is also dependent on the pore volume and average diffusive jump length in the material.

\subsection{Temperature dependence of gas sorption}

Sorption measurements were performed with $\mathrm{CO}_{2}, \mathrm{CH}_{4}, \mathrm{~N}_{2}$, and $\mathrm{O}_{2}$ on silica derived from thermally oxidized PDMS and titania-crosslinked PDMS. Langmuir isotherms for $\mathrm{CO}_{2}$ were collected at $35^{\circ} \mathrm{C}$ while sorption coefficients were obtained at pressures of 50 and 100 psia at temperatures of 35,50 , and $70^{\circ} \mathrm{C}$. Data were not collected for $\mathrm{He}$ or $\mathrm{H}_{2}$ due to the extremely low sorption of these gases relative to the sensitivity of the pressure transducers used in this experiment. The temperature dependence of the sorption coefficients of the varying gases and silica materials are shown in Fig. 6 and their respective enthalpies of sorption and preexponential factors are found in Table 4. 

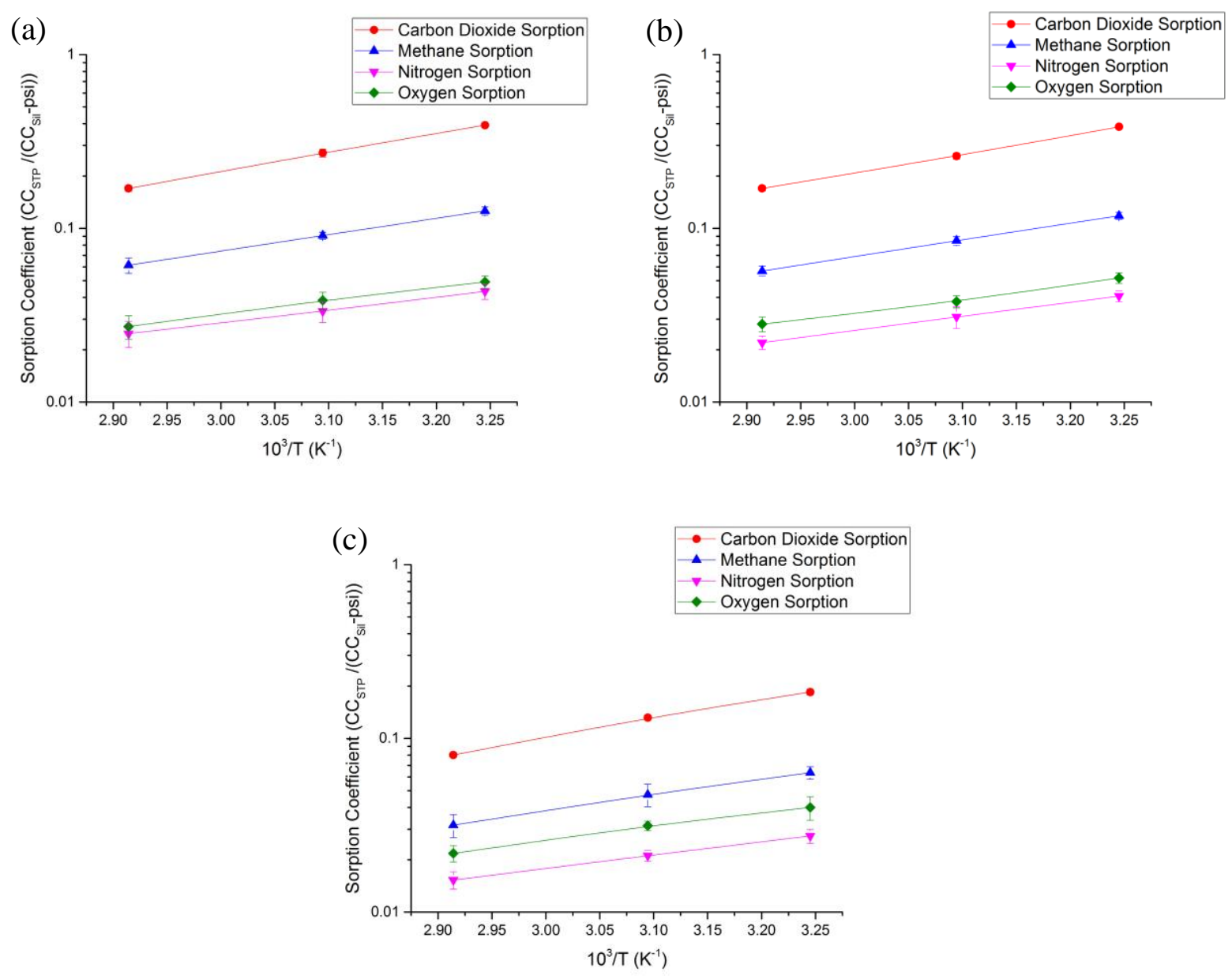

Fig. 6. Soption temperature dependence of $\mathrm{CO}_{2}, \mathrm{CH}_{4}, \mathrm{~N}_{2}$, and $\mathrm{O}_{2}$ at 50 psia in (a) regular, (b) heat treated, and (c) titania-crosslinked silica with error bars representing $95 \%$ confidence intervals

The recorded sorption coefficients and enthalpies of sorption increase with gas critical temperature where $\mathrm{N}_{2}<\mathrm{O}_{2}<\mathrm{CH}_{4}<\mathrm{CO}_{2}$. This trend is expected since the gas condensability increases with critical temperature and allows for more gas to condense into the sorbed state in the pores of the membrane. Further, all sorption coefficients for each gas decrease with increasing temperature, which is reflected in the negative enthalpies of sorption recorded in each gas. This change in enthalpy in rigid porous materials is associated with the condensation of gases and their interaction with functional groups in the material. Since the enthalpies of sorption of these gases are much more negative than that of their enthalpies of condensation, this implies a significant interaction with the functional groups in the material. It is likely that free silanol or siloxane groups in the silica stabilize the sorbed state of these gases. 
Table 4. Enthalpies of sorption and pre-exponential factors for $\mathrm{CO}_{2}, \mathrm{CH}_{4}, \mathrm{~N}_{2}$, and $\mathrm{O}_{2}$ at 50 psia in regular, heat treated, and titania-crosslinked silica between 35 to $70^{\circ} \mathrm{C}$ with $95 \%$ confidence intervals.

\begin{tabular}{|c|c|c|c|c|}
\hline \multirow[t]{2}{*}{ Silica Membranes: } & \multicolumn{4}{|c|}{ Sorption Energetics } \\
\hline & $\mathrm{CO}_{2}$ & $\mathrm{CH}_{4}$ & $\mathrm{~N}_{2}$ & $\mathrm{O}_{2}$ \\
\hline & \multicolumn{4}{|c|}{$\Delta H_{S}(\mathrm{~kJ} / \mathrm{mol})$} \\
\hline Regular Silica & $-21.0 \pm 0.3$ & $-18.5 \pm 0.5$ & $-14.6 \pm 0.8$ & $-15.0 \pm 0.7$ \\
\hline Heat Treated Silica & $-20.4 \pm 0.2$ & $-18.5 \pm 0.2$ & $-15.4 \pm 0.5$ & $-15.5 \pm 0.4$ \\
\hline Titania-Crosslinked Silica & $-21.1 \pm 0.2$ & $-18.2 \pm 0.8$ & $-14.6 \pm 0.5$ & $-15.2 \pm 0.7$ \\
\hline \multicolumn{5}{|c|}{$\mathbb{S}_{0}\left(10^{-5} \mathrm{CC}_{\mathrm{STP}} /\left(\mathrm{CC}_{\mathrm{Sil}}\right.\right.$-psi $\left.)\right)$} \\
\hline Regular Silica & $10.7 \pm 2.6$ & $9.1 \pm 1.5$ & $14.4 \pm 4.1$ & $13.8 \pm 3.5$ \\
\hline Heat Treated Silica & $13.0 \pm .9$ & $8.7 \pm .8$ & $9.8 \pm 1.9$ & $12.0 \pm 1.8$ \\
\hline Titania-Crosslinked Silica & $5.0 \pm .4$ & $4.1 \pm 1.4$ & $9.1 \pm 1.7$ & $10.9 \pm 2.6$ \\
\hline
\end{tabular}

The $\mathrm{CO}_{2}$ Langmuir isotherms are reported in Fig. 7 below with the respective fitting parameters in Table 5. The silica and thermally soaked silica showed a higher sorption capacity and similar Langmuir affinity compared to the titania-crosslinked silica. In contrast, the silica and thermally soaked silica showed little noticeable difference in either the sorption capacity or Langmuir affinity. These results are consistent with the pore size distribution data that shows similar pore volumes between the PDMS derived silicas and a reduction in volume in the titania-crosslinked silica. However, the physisorption data suggest a much lower sorption capacity for the titaniacrosslinked silica than was observed. This result indicates that most of the titania-crosslinked silica pore volume may lie in the 9-11 A range, which are undetectable with $\mathrm{CO}_{2}$ and $\mathrm{N}_{2}$ physisorption. The similar Langmuir affinities are expected due to the similar materials involved in these experiments. The prexponential factors and enthalpies of sorption for each of these materials are similar, and are also consistent with results for sol-gel derived silicas. Work by Benes et al. reported enthalpies of sorption for $\mathrm{CO}_{2}, \mathrm{CH}_{4}, \mathrm{~N}_{2}$, and $\mathrm{O}_{2}$ of $-24,-20,-17$, and -16 respectively for sol-gel derived silica, which are similar to the values reported in this study [12]. 


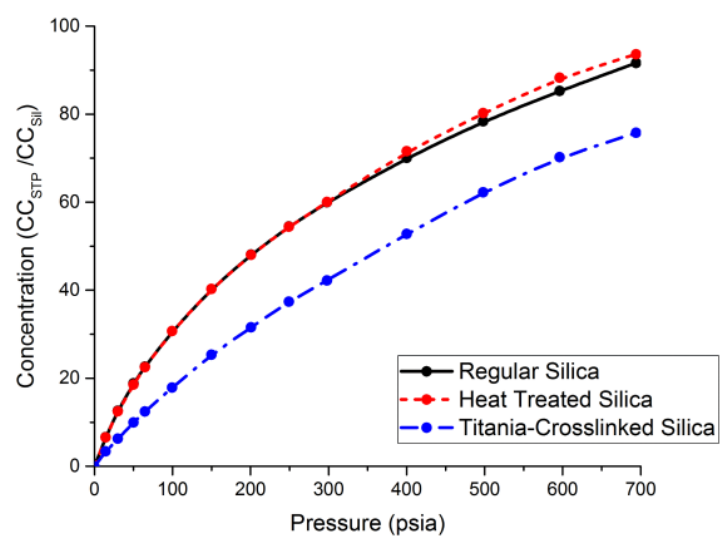

Fig. 7. Langmuir isotherms of $\mathrm{CO}_{2}$ at $35^{\circ} \mathrm{C}$ in regular, heat treated, and titania-crosslinked silica between 15 to 700 psia.

Table 5. Langmuir sorption fitting parameters for $\mathrm{CO}_{2}$ at $35^{\circ} \mathrm{C}$ in regular, heat treated, and titania-crosslinked silica between 15 to 700 psia with $95 \%$ confidence intervals.

\begin{tabular}{|l|l|l|}
\hline \multirow{2}{*}{ Silica Membranes: } & \multicolumn{2}{l|}{ Langmuir Fitting Parameters } \\
\cline { 2 - 3 } & $C_{A}^{\prime}\left(\mathrm{CC}_{\mathrm{STP}} / \mathrm{CC}_{\mathrm{Sil}}\right)$ & $b_{A}(1 / \mathrm{psia})$ \\
\hline Regular Silica & $135 \pm 9$ & $0.0028 \pm 0.0004$ \\
\hline Heat Treated Silica & $132 \pm 11$ & $0.0030 \pm 0.0004$ \\
\hline Titania-Crosslinked Silica & $112 \pm 12$ & $0.0023 \pm 0.0005$ \\
\hline
\end{tabular}

An unexpected observation is the low Langmuir affinities of these silicas compared to other materials such as CMS. The magnitude of the enthalpy of sorption for $\mathrm{CO}_{2}$ in these silicas is significantly higher than the enthalpy of sorption for $\mathrm{CO}_{2}$ in $\mathrm{CMS}$. This difference implies a higher energetic affinity to the silica materials [55]. However, the reduction in affinity may reflect a much lower entropy of gas molecules in the sorbed state between these two types of materials. As shown in Eq. (11) the pre-exponential factor for Langmuir affinity is dependent on the difference in entropy between the free gas state and the sorbed gas state. A reduction in the degrees of freedom of sorbed gases in the silicas versus CMS could result in the lower Langmuir affinity. Further details of this analysis are provided in the appendix.

\subsection{Temperature dependence of gas diffusion}

Permeation and sorption data were combined through Eq. (1) to calculate average diffusion coefficients for $\mathrm{CO}_{2}, \mathrm{O}_{2}, \mathrm{~N}_{2}$, and $\mathrm{CH}_{4}$ at temperatures of 35 and $70^{\circ} \mathrm{C}$ at 50 psia. Additionally, diffusion coefficients were indirectly calculated at 50 and $100^{\circ} \mathrm{C}$ by combining Eqs. (1), (5), and (7). Eqs. (8) and (9) were then used to calculate the activation energies of diffusion and their respective pre-exponential factors for each gas and material in this study. The average diffusion coefficients are reported in Fig. 8 while the activation energies of diffusion and pre-exponential factors are tabulated in Table 6. 
(a)

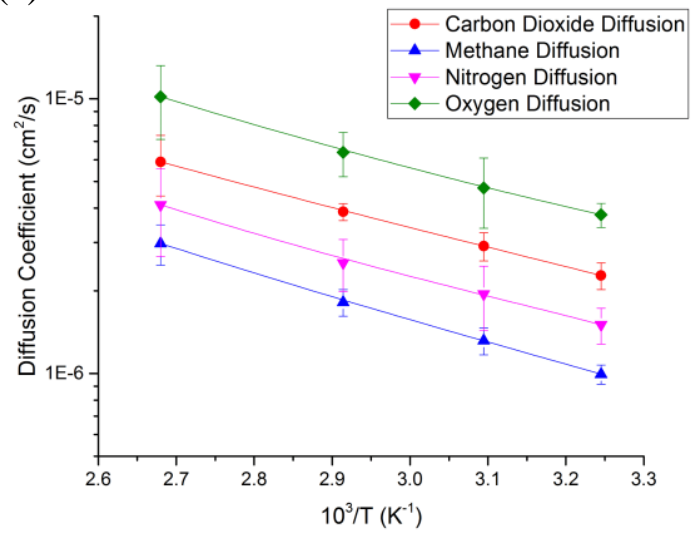

(b)

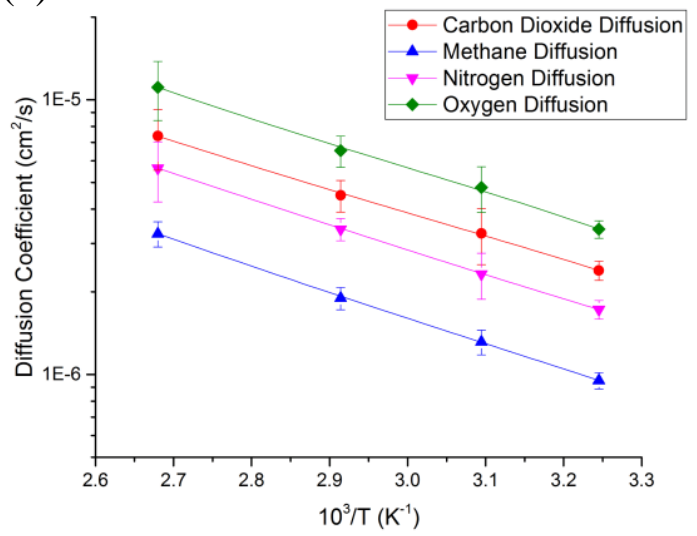

Fig. 8. Diffusion temperature dependence of $\mathrm{CO}_{2}, \mathrm{CH}_{4}, \mathrm{~N}_{2}$, and $\mathrm{O}_{2}$ at 50 psia in (a) regular and (b) heat treated silica with error bars representing $95 \%$ confidence intervals.

The average diffusivity of each gas increases with temperature and can be seen in the positive activation energy of diffusion for each gas. This activation energy describes the energy required for a diffusing molecule to make an activated jump through a critical utramicropore in a rigid porous material. This activation energy is dependent on the average diameter of the critical ultramicropores and the size of the penetrant diffusing through them. These data show that the activation energy of diffusion increases with gas diameter where $\mathrm{CO}_{2}<\mathrm{O}_{2}<\mathrm{N}_{2}<\mathrm{CH}_{4}$. This also has the effect of decreasing the overall diffusion due to the higher energy barrier to diffusion and is reflected in the average diffusion coefficients where $\mathrm{CH}_{4}<\mathrm{N}_{2}<\mathrm{CO}_{2}<\mathrm{O}_{2}$. The interesting exception to this observation is $\mathrm{O}_{2}$ which has a slightly higher diffusion than $\mathrm{CO}_{2}$. This difference may be caused by competing entropic and energetic effects on the diffusion of these molecules through the critical ultramicropores.

Table 6. Activation energies and pre-exponential factors of diffusion for $\mathrm{CO}_{2}, \mathrm{CH}_{4}, \mathrm{~N}_{2}$, and $\mathrm{O}_{2}$ at 50 psia in regular and heat treated silica at 35 and $70^{\circ} \mathrm{C}$ with $95 \%$ confidence intervals.

\begin{tabular}{|l|l|l|l|l|}
\hline Silica Membranes: & \multicolumn{2}{l|}{ Diffusion Energetics } \\
\cline { 2 - 5 } & $\mathrm{CO}_{2}$ & $\mathrm{CH}_{4}$ & $\mathrm{~N}_{2}$ & $\mathrm{O}_{2}$ \\
\hline \multicolumn{7}{c|}{$E_{D}(\mathrm{~kJ} / \mathrm{mol})$} \\
\hline Regular Silica & $13.8 \pm 0.4$ & $15.9 \pm 0.5$ & $14.5 \pm 1.0$ & $14.1 \pm 0.9$ \\
\hline Heat Treated Silica & $16.0 \pm 0.6$ & $18.1 \pm 0.3$ & $17.1 \pm 0.6$ & $17.1 \pm 0.6$ \\
\hline \multicolumn{7}{c}{$D_{0}\left(10^{-4} \mathrm{~cm}^{2} / \mathrm{s}\right)$} & \\
\hline Regular Silica & $5.1 \pm 1.3$ & $5.0 \pm 1.0$ & $4.4 \pm 1.6$ & $9.4 \pm 3.4$ \\
\hline Heat Treated Silica & $12.7 \pm 3.0$ & $11.1 \pm 1.4$ & $13.8 \pm 3.2$ & $27.5 \pm 6.2$ \\
\hline
\end{tabular}

When comparing the regular and heat treated silica, the heat treated silica shows a much higher activation energy of diffusion compared to the regular silica. This higher activation energy reflects a tightening of the critical ultramicropores that increases the energy required for penetrants to make a diffusive jump. This decrease in diameter may be related to the 
densification of the silica matrix during the heat treatment. After heat treatment, the density of the silica increases by $3 \%$ from 1.311 to $1.351 \mathrm{~g} / \mathrm{cm}^{3}$ and seems to tighten the ultramicropores while having little effect on the micropores. When comparing these silicas to CMS, the activation energy of diffusion of penetrants in silica is on average much lower than CMS and implies a larger average diameter of the critical ultramicropores compared to CMS. Similarly the average diffusion coefficients of the silica materials average 1-2 orders magnitude higher than that of CMS. This difference is probably due to the high diffusive jump length associated with the large volume of mesopores in the silica compared CMS [55]. The similar volume of these mesopores in the regular and heat treated silica also help explain why these two materials show similar magnitudes of diffusion.

\subsection{Entropic and energetic selectivities of notable gas pairs and silica ultramicropore morphology}

The overall permselectivities of the studied membranes are a product of their sorption and diffusion selectivities according to Eq. (4). A comparison of these selectivies was tabulated in Table 7 for the PDMS derived silica for 4 gas pairs of $\mathrm{CO}_{2} / \mathrm{CH}_{4}, \mathrm{O}_{2} / \mathrm{N}_{2}, \mathrm{CO}_{2} / \mathrm{N}_{2}$, and $\mathrm{CH}_{4} / \mathrm{N}_{2}$ at $50 \mathrm{psi}$ and $35^{\circ} \mathrm{C}$. The dominance of sorption or diffusion selectivity varies between gas pairs where sorption selectivity tends to dominate the more permselective gas pairs with sorption selectivites as high as 9.04 for $\mathrm{CO}_{2} / \mathrm{N}_{2}$. This pair was expected to have the highest sorption selectivity due to having the highest ratio in critical temperature. In contrast, the diffusion selectivity is very low in these silica materials and the highest recorded diffusion selectivity is 3.82 for $\mathrm{O}_{2} / \mathrm{CH}_{4}$.

Table 7. Permeation, sorption, and diffusion selectivities of $\mathrm{CO}_{2} / \mathrm{CH}_{4}, \mathrm{O}_{2} / \mathrm{N}_{2}, \mathrm{CO}_{2} / \mathrm{N}_{2}, \mathrm{CO}_{2} / \mathrm{O}_{2}$, $\mathrm{O}_{2} / \mathrm{CH}_{4}$, and $\mathrm{CH}_{4} / \mathrm{N}_{2}$ gas pairs in regular and heat treated silica at $35^{\circ} \mathrm{C}$ and 50 psia with $95 \%$ confidence intervals.

\begin{tabular}{|l|l|l|l|l|}
\hline Silica Membranes: & Gas Pairs $\left(50\right.$ psi and 35 $\left.{ }^{\circ} \mathrm{C}\right)$ \\
\cline { 2 - 5 } & $\mathrm{CO}_{2} / \mathrm{CH}_{4}$ & $\mathrm{O}_{2} / \mathrm{N}_{2}$ & $\mathrm{CO}_{2} / \mathrm{N}_{2}$ & $\mathrm{CH}_{4} / \mathrm{N}_{2}$ \\
\hline \multicolumn{5}{|l|}{ Permselectivity $\left(P_{A} / P_{B}\right)$} \\
\hline Regular Silica & $7.12 \pm 0.9$ & $2.85 \pm 0.4$ & $13.7 \pm 2.1$ & $1.92 \pm 0.2$ \\
\hline Heat Treated Silica & $8.16 \pm 0.8$ & $2.49 \pm 0.1$ & $13.1 \pm 1.0$ & $1.60 \pm 0.1$ \\
\hline \multicolumn{5}{|c|}{ Sorption Selectivity $\left(\mathbb{S}_{A} / \mathbb{S}_{B}\right)$} \\
\hline Regular Silica & $3.11 \pm 0.2$ & $1.13 \pm 0.2$ & $9.04 \pm 1.0$ & $2.90 \pm 0.3$ \\
\hline Heat Treated Silica & $3.25 \pm 0.2$ & $1.27 \pm 0.1$ & $9.43 \pm 0.7$ & $2.90 \pm 0.3$ \\
\hline \multicolumn{5}{c}{ Diffusion Selectivity $\left(D_{A} / D_{B}\right)$} \\
\hline Regular Silica & $2.29 \pm 0.3$ & $2.51 \pm 0.5$ & $1.51 \pm 0.3$ & $0.66 \pm 0.1$ \\
\hline Heat Treated Silica & $2.51 \pm 0.3$ & $1.93 \pm 0.3$ & $1.33 \pm 0.2$ & $0.56 \pm 0.1$ \\
\hline
\end{tabular}

The diffusion selectivity is also the product of the energetic and entropic contributions according to Eq. (13) and their contributions for each gas pair is tabulated in Table 8. For each gas pair there was not a significant difference in either the energetic or entropic selectivity for the regular or heat treated silica. While the heat treated silica has a higher energy of diffusion for each gas, 
the relative difference in the energies of diffusion between gases changed very little. This difference resulted in little change in the energetic contribution to diffusion selectivity. The entropic selectivity also did not change much due to the critical ultramicropore geometry. Unlike CMS with a distinct slit-like critical ultramicropore geometry, the silica ultramicropore's geometry probably has limited shape discrimination. The highest observed entropic selectivity was 2.47 for $\mathrm{O}_{2} / \mathrm{CH}_{4}$, but CMS materials report entropic selectivies as high as 10.6 for this gas pair [55].

Table 8. Energetic and entropic diffusion selectivities of $\mathrm{CO}_{2} / \mathrm{CH}_{4}, \mathrm{O}_{2} / \mathrm{N}_{2}, \mathrm{CO}_{2} / \mathrm{N}_{2}, \mathrm{CO}_{2} / \mathrm{O}_{2}$, $\mathrm{O}_{2} / \mathrm{CH}_{4}$, and $\mathrm{CH}_{4} / \mathrm{N}_{2}$ gas pairs in regular and heat treated silica at $35^{\circ} \mathrm{C}$ and 50 psia with $95 \%$ confidence intervals.

\begin{tabular}{|l|l|l|l|l|}
\hline Silica Membranes: & Gas Pairs $\left(50\right.$ psi and $\left.35^{\circ} \mathrm{C}\right)$ \\
& \multicolumn{5}{l|}{} \\
& $\mathrm{CO}_{2} / \mathrm{CH}_{4}$ & $\mathrm{O}_{2} / \mathrm{N}_{2}$ & $\mathrm{CO}_{2} / \mathrm{N}_{2}$ & $\mathrm{CH}_{4} / \mathrm{N}_{2}$ \\
\hline \multicolumn{5}{|c|}{ Energetic Selectivity } \\
\hline Regular Silica & $2.3 \pm 0.6$ & $1.2 \pm 0.6$ & $1.3 \pm 0.6$ & $0.6 \pm 0.3$ \\
\hline Heat Treated Silica & $2.3 \pm 0.6$ & $1.0 \pm 0.3$ & $1.5 \pm 0.5$ & $0.7 \pm 0.2$ \\
\hline \multicolumn{5}{|l}{ Entropic Selectivity } \\
\hline Regular Silica & $1.0 \pm 0.3$ & $2.2 \pm 1.1$ & $1.2 \pm 0.5$ & $1.2 \pm 0.5$ \\
\hline Heat Treated Silica & $1.2 \pm 0.3$ & $2.0 \pm 0.7$ & $0.9 \pm 0.3$ & $0.8 \pm 0.2$ \\
\hline
\end{tabular}

Overall the heat treatment performed on these silica membranes was insufficient to significantly increase the diffusion selectivity of these membranes. However, it may be possible to alter oxidative thermolysis cycle and tighten the critical ultramicropores to the point that limited shape discrimination can occur. It may also be possible that the titania crosslinking could alter the geometry of the critical ultramicropores for increased entropic selectivity, however improvement of the fabrication process is necessary before this can be explored.

\section{Conclusions}

Temperature has a significant effect on the transport properties of gas permeation, diffusion, and sorption based on the energetics of these properties. As expected, these silica materials universally showed an increase in diffusion and a decrease in sorption with temperature. The positive activation energies of diffusion and negative enthalpies of sorption were very close in magnitude for many of the tested gas, which resulted in activation energies of permeation that were either positive, negative, or near zero depending upon the penetrant gas. This understanding of temperature dependence in combination with pore size distribution data sheds light on the morphology of these silica materials and allows for a better understanding of why their transport properties behave as they do. More importantly, this understanding can help in the design of new silica materials that are more entropically selective. Ultimately the tuning of the entropic selectivity can allow for improved separation performance that exceed the polymer upper bound. 


\section{Acknowledgements}

The authors acknowledge the support of Neha Bighane for inspiring this work. The authors also acknowledge the support of the Georgia Institute of Technology and the Office of Basic Energy Science of the U.S. Department of Energy [DE-FG02-04ER15510] for funding this project.

\section{Appendix: Entropic and energetic effects of gas sorption on different materials}

This analysis is somewhat analogous to the study of entropic and energetic diffusion selectivity of different gases permeating through the pores of a rigid membrane. This analysis will instead focus on the entropic and energetic selectivity of sorption of $\mathrm{CO}_{2}$ between CMS and Silica materials. This analysis will explain the pronounced difference in Langmuir affinity between these materials.

For sorption of the same gas in two separate materials at the same temperature and pressure, the relative sorption of gas between the two materials can be calculated in Eq. (A.1) by combining Eqs. (3) and (4). In this comparison case, results from Shilu Fu on the sorption properties of CMS derived from the argon pyrolysis 6FDA:BPDA(1:1)/DETDA at $550^{\circ} \mathrm{C}$ are compared to the regular silica in Table A.1 [55].

$$
\frac{\mathbb{S}_{C M S}}{\mathbb{S}_{S i l}}=\frac{C_{C M S} / p_{A}}{C_{S i l} / p_{A}}=\frac{C_{h, A}^{\prime} b_{C M S}}{C_{h, B}^{\prime} b_{S i l}} \frac{\left(1+b_{S i l} p_{A}\right)}{\left(1+b_{C M S} p_{A}\right)}
$$

Table A.1. Sorption parameters for $\mathrm{CO}_{2}$ at $35^{\circ} \mathrm{C}$ in regular silica and $\mathrm{CMS}$ derived from the argon pyrolysis of $6 \mathrm{FDA}: \mathrm{BPDA}(1: 1) / \mathrm{DETDA}$ at $550^{\circ} \mathrm{C}$.

\begin{tabular}{|l|l|l|l|}
\hline \multirow{2}{*}{ Silica Membranes: } & \multicolumn{3}{l|}{ Sorption Properties } \\
\cline { 2 - 4 } & $C^{\prime}\left(\right.$ CC $\left._{\text {STp }} / C_{\text {Sil }}\right)$ & $b(1 / \mathrm{psia})$ & $\Delta H_{S}(\mathrm{~kJ} / \mathrm{mol})$ \\
\hline Regular Silica & 135 & 0.0028 & -21.0 \\
\hline CMS (6FDA:BPDA(1:1)/DETDA at $\left.550^{\circ} \mathrm{C}\right)$ & 127 & 0.047 & -9.1 \\
\hline
\end{tabular}

By substituting the sorption parameters for the CMS and silica into Eq. (A.1) at 50 psia, the following sorption selectivity is found.

$$
\begin{aligned}
\frac{\mathbb{S}_{C M S}}{\mathbb{S}_{S i l}}=\frac{C_{h, A}^{\prime} b_{C M S}}{C_{h, B}^{\prime} b_{S i l}} & \frac{\left(1+b_{S i l} p_{A}\right)}{\left(1+b_{C M S} p_{A}\right)} \\
= & \frac{127 C_{S T P} C^{-1}}{134 C_{S T P} C^{-1}} \frac{0.047 \mathrm{psia}^{-1}}{0.0028 \mathrm{psia}^{-1}} \frac{\left(1+(50 \mathrm{psia})\left(0.0028 \mathrm{psia}^{-1}\right)\right)}{\left(1+(50 \mathrm{psia})\left(0.047 \mathrm{psia}^{-1}\right)\right)} \\
= & (0.948)(17)(0.34)=5.4
\end{aligned}
$$

This shows that the CMS sorbs 5.4 times as much $\mathrm{CO}_{2}$ at $35^{\circ} \mathrm{C}$ and 50 psia than the silica. Interestingly, the majority of this difference comes from the ratio of Langmuir affinity between these two materials, not the sorption capacity. 
To evaluate differences in this Langmuir affinity of $\mathrm{CO}_{2}$ between these materials, Eqs. (4), (10), and (11) were combined to yield Eq. (A.2). This equation shows an entropic and energetic Langmuir selectivity, which is analogous to that of the diffusion selectivity.

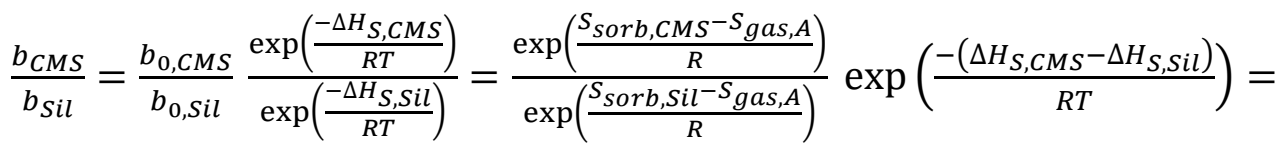

$$
\begin{aligned}
& \underbrace{\exp \left(\frac{S_{\text {Sorb }, C M S}-S_{\text {Sorb }, \text { Sil }}}{R}\right)} \exp \left(\frac{-\left(\Delta H_{S, C M S}-\Delta H_{S, S i l}\right)}{R T}\right) \\
& \text { Entropic Selectivity Energetic Selectivity }
\end{aligned}
$$

Statistical thermodynamics describe the Langmuir affinity through Eq. (A.3) [56].

$$
b_{C M S}=\frac{h^{3}}{(2 \pi m)^{3 / 2}(k T)^{1 / 2}} \frac{F_{\text {Sor } b, C M S}}{F_{\text {gas }}} \exp \left(-\frac{\Delta H_{S, C M S}}{R T}\right)
$$

Where $F_{\text {Sorb,CMS }}$ is the partition function of a gas in a sorbed state in CMS, $F_{g a s}$ is the partition function of a free gas, and $\Delta H_{S, C M S}$ is the enthalpy difference between a gas in its sorbed and free gas states in CMS. These partition functions can then be expressed as the product of their translational $\left(F_{\text {trans }}\right)$, rotational $\left(F_{\text {rot }}\right)$, and vibrational $\left(F_{v i b}\right)$ contributions and the degrees of freedom $(n)$ of each mode in Eqs. (A.4) and (A.5) [56].

$$
\begin{aligned}
& F_{\text {sorb }}=F_{s, \text { trans }}^{n} F_{s, \text { rot }}^{n} F_{s, \text { vib }}^{n} \\
& F_{\text {gas }}=F_{g, \text { trans }}^{n} F_{g, \text { rot }}^{n} F_{g, v i b}^{n}
\end{aligned}
$$

By combining Eqs. (A.2), (A.3), (A.4), and (A.5) the entropic contribution of the Langmuir selectivity between two materials can be expressed in Eq. (A.6).

$$
\frac{b_{0, C M S}}{b_{0, S i l}}=\frac{F_{\text {sorb }, C M S}}{F_{\text {gas }, A}} \frac{F_{\text {gas }, A}}{F_{\text {sorb }, \text { Sil }}}=\frac{F_{s, C M S, \text { trans }}^{n} F_{s, C M S, \text { rot }}^{n} F_{S, C M S, v i b}^{n}}{F_{s, S i l, t r a n s}^{n} F_{s, \text { Sil }, \text { rot }}^{n} F_{s, \text { Sil,vib }}^{n}}
$$

This expression shows the difference in the entropic Langmuir selectivity arises from a reduction in the degrees of freedom in a sorbed state. The value of this entropic selectivity can be explicitly calculated through the partition functions in Eqs. (A.7), (A.8), and (A.9) for an ideal gas in a one dimensional box [46].

$$
\begin{aligned}
& F_{\text {trans }}=d_{t}\left(\frac{2 \pi m k T}{h^{2}}\right)^{1 / 2} \\
& F_{\text {rot }}=\left(\frac{8 \pi^{2} I k T}{h^{2}}\right)^{1 / 2} \\
& F_{v i b}=\frac{\exp \left(-\frac{h v}{2 k T}\right)}{\left(1-\exp \left(-\frac{h v}{2 k T}\right)\right)}
\end{aligned}
$$


Where $d_{t}$ is the average diameter of a pore where gas can exist in a sorbed state or free state, $m$ is the mass of a molecule, $I$ is the rotational inertia of a molecule, and $v$ is the vibrational frequency of a molecule [46].

The degrees of freedom of each of these modes depends on the gas. $\mathrm{CO}_{2}$ is linear with 3 atoms, which gives it 3 translational, 2 rotational, and 4 vibrational degrees of freedom in its free state [56]. The entropic Langmuir selectivity appears to arise from a difference in the degrees of freedom that exist between a sorbed state in silica versus $\mathrm{CMS}$. For $\mathrm{CO}_{2}$ existing in a sorbed state in either material, it is anticipated that all rotational and vibrational degrees of freedom will be preserved. Similarly, $\mathrm{CO}_{2}$ is expected to lose at least one degree of translational freedom in the Z-direction since the molecule is bound to the surface of the pore walls of both materials. The difference between these materials may reflect a loss of an additional 2 translational degrees of freedom in the silica. The low enthalpy of sorption in the CMS means that the $\mathrm{CO}_{2}$ is less tightly bound in the CMS compared to the silica and may allow it to "slide" across the surface of the CMS pores in the $\mathrm{X}$ and $\mathrm{Y}$ directions. The high enthalpy of sorption for $\mathrm{CO}_{2}$ in silica may mean that it is more tightly sorbed in the silica and is probably polarized by the siloxane groups in the silica backbone. The polarization may force the $\mathrm{CO}_{2}$ to be "stuck" on the walls of the silica pores and less able to move in the $\mathrm{X}$ and $\mathrm{Y}$ directions. This hypothesis can be visualized in Fig. A.1 below.
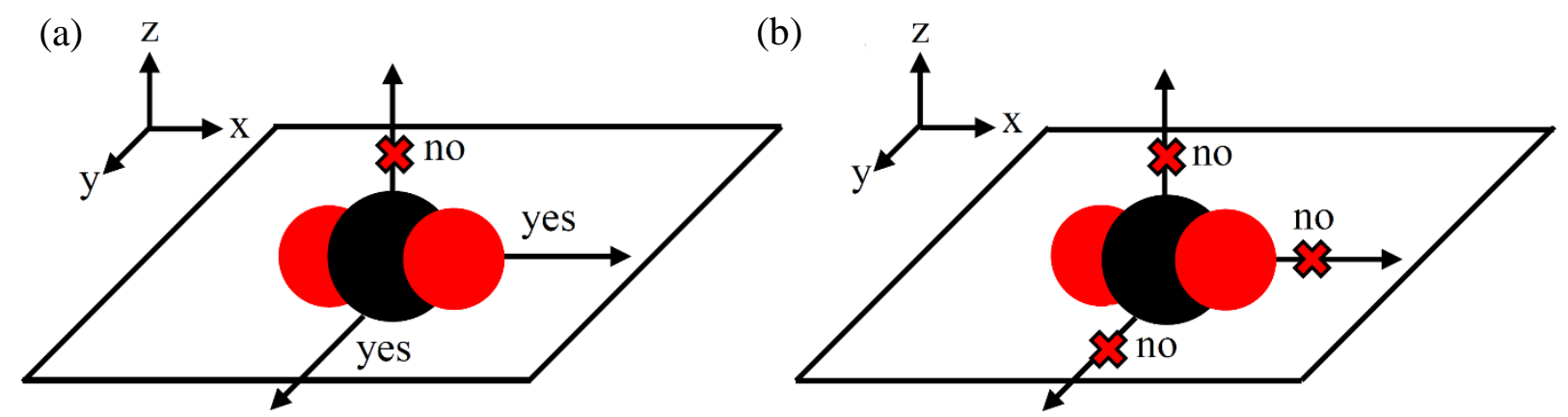

Fig. A.1. A $\mathrm{CO}_{2}$ molecule bound to the surface of (a) CMS can move in the $\mathrm{X}$ and $\mathrm{Y}$ directions, but $\mathrm{CO}_{2}$ bound to the surface of (b) silica is so tightly bound that it loses translational degrees of freedom in the $\mathrm{X}$ and $\mathrm{Y}$ directions.

These different states can be mathematically expressed through Eqs. (A.10), (A.11), and (A.12).

$$
\begin{aligned}
& F_{\mathrm{CO}_{2}}=F_{g, \text { trans }}^{3} F_{g, r o t}^{2} F_{g, v i b}^{4} \\
& F_{\text {sorb }, C M S}=F_{s, C M S, \text { trans }}^{2} F_{g, \text { rot }}^{2} F_{g, v i b}^{4} \\
& F_{\text {sorb }, \text { Sil }}=F_{s, \text { Sil,trans }}^{0} F_{g, \text { rot }}^{2} F_{g, v i b}^{4}=F_{g, r o t}^{2} F_{g, v i b}^{4}
\end{aligned}
$$

Eqs. (A.10), (A.11), and (A.12) can then be substituted into Eq. (A.6) to yield Eq. (A.13). 


$$
\begin{aligned}
& \frac{b_{0, A}}{b_{0, B}}=\frac{F_{\text {sorb }, C M S}}{F_{g a s, A}} \frac{F_{g a s, A}}{F_{\text {sorb }, \text { Sil }}}=\frac{F_{s, C M S, \text { trans }}^{2} F_{g, r o t}^{2} F_{g, v i b}^{4}}{F_{g, r o t}^{2} F_{g, v i b}^{4}}= \\
& F_{S, C M S, t r a n s}^{2}
\end{aligned}
$$

Eq. (A.13) can then be combined with Eqs. (A.2) and (A.7) to yield Eq. (A.14).

$$
\begin{array}{r}
\frac{b_{0, C M S}}{b_{0, S i l}}=\frac{b_{C M S}}{b_{S i l}} \frac{\exp \left(\frac{-\Delta H_{S, S i l}}{R T}\right)}{\exp \left(\frac{-\Delta H_{S, C M S}}{R T}\right)}=\frac{b_{C M S}}{b_{S i l}} \exp \left(\frac{\Delta H_{S, C M S}-\Delta H_{S, S i l}}{R T}\right)= \\
d_{t}^{2}\left(\frac{2 \pi m k T}{h^{2}}\right)
\end{array}
$$

Eq. (A.14) was used to compare experimental data to the theoretical calculation of entropic selectivity at $35^{\circ} \mathrm{C}$. Before the theoretical calculation was completed, the average pore width was approximated from $\mathrm{CO}_{2}$ physisorption data through Eq. (A.15) [57].

$$
d_{t} \approx \frac{\int_{W_{1}}^{W_{2}}\left(W \cdot \frac{d V(W)}{d W}\right) d W}{\int_{W_{1}}^{W_{2}}\left(\frac{d V(W)}{d W}\right) d W}
$$

Where $W_{1}$ is the lower bound of pore width, $W_{2}$ is the upper bound of pore width, and $\frac{d V(W)}{d W}$ is the differential pore volume of a material determined by $\mathrm{CO}_{2}$ physisorption data. The $\mathrm{CO}_{2}$ physisorption data for CMS derived from the argon pyrolysis 6FDA:BPDA(1:1)/DETDA at $550^{\circ} \mathrm{C}$ is reported in Fig. A.2.

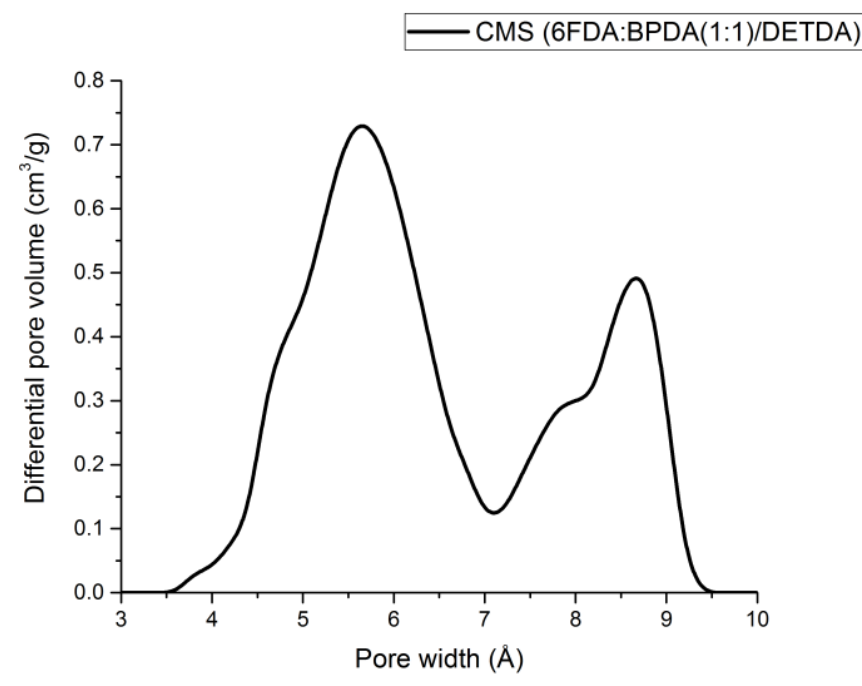

Fig. A.2. Pore size distribution from $\mathrm{CO}_{2}$ physisorption data of $\mathrm{CMS}$ derived from argon pyrolysis 6 FDA:BPDA( $1: 1) / \mathrm{DETDA}$ at $550^{\circ} \mathrm{C}$

The pore size distribution of CMS derived from 6FDA:BPDA(1:1)/DETDA at $550^{\circ} \mathrm{C}$ was numerically integrated using Eq. (A.15) and the average pore width was calculated to be $6.52 \AA$. This pore width was used in Eq. (A.14) with experimental data for the following calculations: Theoretical: 


$$
\begin{aligned}
& d_{t}^{2}\left(\frac{2 \pi m k T}{h^{2}}\right) \\
& =\left(6.52 \times 10^{-10} \mathrm{~m}\right)^{2}\left(\frac{2 \pi\left(7.31 \times 10^{-26} \mathrm{~kg}\right)\left(1.38 \times 10^{-23} \mathrm{~m}^{2} \mathrm{~kg} \mathrm{~s}^{-2} \mathrm{~K}^{-1}\right)(308.15 \mathrm{~K})}{\left(6.63 \times 10^{-34} \mathrm{~m}^{2} \mathrm{~kg} \mathrm{~s}^{-1}\right)^{2}}\right)=1890
\end{aligned}
$$

Experimental:

$$
\begin{aligned}
\frac{b_{C M S}}{b_{S i l}} \exp \left(\frac{\Delta H_{S, C M S}-\Delta H_{S, S i l}}{R T}\right) & \\
= & \frac{\left(0.047 \mathrm{psia}^{-1}\right)}{\left(0.0028 \mathrm{psia}^{-1}\right)} \exp \left(\frac{\left(-21 \mathrm{~kJ} \mathrm{~mol}^{-1}\right)-\left(-9.1 \mathrm{~kJ} \mathrm{~mol}^{-1}\right)}{\left(.008314 \mathrm{~kJ} \mathrm{~mol}^{-1} \mathrm{~K}^{-1}\right)(308.15 \mathrm{~K})}\right)=1750
\end{aligned}
$$

Clearly these results are relatively close and only differ by $7.4 \%$, which may support the validity of the predictions made by this simple theoretical model. Overall, it seems that the difference in Langmuir affinity observed between the CMS and silica comes from a difference in translational degrees of freedom available to sorbed $\mathrm{CO}_{2}$. What this means is that while $\mathrm{CO}_{2}$ binds very tightly to the silica, it cannot move and thus results in a less thermodynamically favorable state of sorption.

\section{References:}

[1] U.S. Geological Survey, 2011, Mineral Commodity Summaries 2011: U.S. Geological Survey, pp. 198

[2] J.M. Ogden, Prospect for building a hydrogen infrastructure, Annual Review of Energy and the Environment, 24 (1999), pp. 227-279

[3] C. Han, D.P. Harrison, Simultaneous shift reaction and carbon dioxide separation for the direct production of hydrogen, Chem. Eng. Technol., 49 (1994), pp. 5875-5883

[4] S. Giessler, L. Jordan, J.C. Diniz da Costa, G.Q. Lu, Performance of hydrophobic and hydrophilic silica membrane reactors for the water gas shift reaction, Sep. Purif. Technol., 32 (2003), pp. 255-264

[5] H.L. Castricum, A. Sah, R. Krieter, D.A. Blank, J.F. Vente, J.E. Elshof, Hydrothermally stable molecular separation membranes from organically linked silica, J. Mater. Chem., 18 (2008), pp. 2150-2158

[6] L.M. Robeson, The upper bound revisited, J. Membr. Sci., 320 (2008), pp. 390-400

[7] N. Bighane, W.J. Koros, Novel silica membranes for high temperature gas separations, J. Membr. Sci., 371 (2011), pp. 254-262

[8] G.P. Fotou, Y.S. Lin, S.E. Pratsinis, Hydrothermal stability of pure and modified microporous silica membranes, J. Mater. Sci., 30 (1995), pp. 2803-2808

[9] A. Li, W. Ling, R. Hughes, The effect of carbon monoxide and steam on the hydrogen permeability of a pd/stainless steel membrane, J. Membr. Sci., 165 (2000), pp. 135-141 
[10] Q. Wei, F. Wang, Z.R. Nie, C.L. Song, Y.L Wang, Q.Y. Li, Highly hydrothermally stable silica membranes for hydrogen separations, J. Phys. Chem. B., 112 (2008), pp. 9354-9359

[11] R.M. de Vos, W.F. Maier, H. Verweij, Hydrophobic silica membranes for gas separations, J. Membr. Sci., 158 (1999), pp. 277-288

[12] N. Benes, A. Nijmeijer, H. Verweij, Microporous silica membranes, In: N.K. Kanellopoulos, Membrane Science and Technology Series, 6: Recent Advances in Gas Separation by Microporous Ceramic Membranes, Elsevier Science B.V., Amsterdam, The Netherlands, 2000, pp. 335-372

[13] H.Y. Ha, S.W. Nam, S.A. Hong, W.K. Lee, Chemical Vapor deposition of hydrogenpermselective silica films on porous glass supports from tetraethylorthosilicate, J. Membr. Sci., 85 (1993), pp. 279-290

[14] H.F. Qureshi, A. Nijmeijer, L. Winnubst, Influence of sol-gel process parameters on the microstructure and performance of hybrid silica membranes, J. Membr. Sci., 446 (2013), pp. 1925

[15] K.-H. Lee, S.-J. Khang, Physical characteristics of a porous silica material formed by pyrolysis of silicone rubber, Ceram. Eng. Sci. Proc., 8 (1987), pp. 85-92

[16] R.S.A. de Lange, J.H.A. Hekkink, K. Keizer, A.J. Burggraaf, Sorption studies of microporous sol-gel modified ceramic membranes, J. Porous Mater., 2 (1995), pp. 141-149

[17] L.V.C. Rees, P. Bruckner, J. Hampson, Sorption of N2, CH4, and CO2 in Silicalite-1, Gas Sep. Purif., 5 (1991), pp. 67-75

[18] T.C. Golden, S. Sircar, Gas adsorption on silicalite, J. Colloid Interface Sci., 162 (1994), pp. $182-188$

[19] V.R. Choudhary, S. Mayadevi, Adsorption of methane, ethane, ethylene, and carbon dioxide on Silicalite-1 zeolites, Zeolites, 17 (1996), pp. 501-507

[20] J. Dunne, R. Mariwala, M. Rao, S. Sircar, R.J. Gorte, A.L. Myers, Heats of adsorption of polar and non-polar gases in homogenous and heterogeneous adsorbents, M.D. LeVan. Fundamentals of Adsorption, Kluwer Academic Publishers, Boston, Massachusetts (1996)

[21] P. Hacarlioglu, L. Achenie, S.T. Oyama, Ab initio studies of silica-based membranes: activation energy of permeation, In: S.T. Oyama, M.S. William, Membrane Science and Technology Series, 14: Inorganic, Polymeric, and Composite Membranes, Elsevier Science B.V., Amsterdam, The Netherlands, 2011, pp. 79-90

[22] T. Yoshioka, E. Nakanishi, T. Tsuru, M. Asaeda, Experimental studies of gas permeation through microporous silica membranes, AIChE J., 47 (2001), pp. 2052-2063

[23] H. Suda, K. Haraya, Gas permeation through micropores of carbon molecular sieve membranes derived from Kapton polyimide, J. Phys. Chem. B., 101 (1997), pp. 3988-3994 
[24] W.J. Koros, A.H. Chan, D.R. Pail, Sorption and transport of various gases in polycarbonate, J. Membr. Sci., 2 (1977), pp. 165-190

[25] W.J. Koros, G.K, Fleming, Membrane-based gas separation, J. Membr. Sci., 104 (1995), pp. $1-80$

[26] K.M. Steel, Carbon membranes for challenging gas separations, The University of Texas at Austin, Ph.D. Dissertation, 2000

[27] W.J. Koros, Transport properties. In: Mark HM. Encyclopedia of Polymer Science and Technology, $3^{\text {rd }}$ Ed, Wiley-Interscience, New York City, USA, 2004

[28] J. Karger, D.M. Ruthven, Diffusion in zeolites and other microporous solids, John Wiley \& Sons Inc., New York City, USA, 1991

[29] R.M. de Vos, H. Verweij, Improved performance of silica membranes for gas separation, J. Membr. Sci., 143 (1998), pp. 37-51

[30] L. Riekert, Sorption, diffusion, and catalytic reaction in zeolites, In: D.D. Eley, H. Pines, P.B. Weisz. Advances in Catalysis, Vol. 21. Elsevier Science B.V., Amsterdam, The Netherlands, 1970

[31] R.M. Barrer, D.E.W. Vaughan, Solution and diffusion of helium and neon in tridymite and cristobalite. Trans. Faraday Soc., 63 (1967), pp. 2275-2290

[32] K. Denbigh, The Principles of Chemical Equilibrium, 4th Ed, Cambridge University Press, London, U.K., 1981

[33] X. Ning, Carbon molecular sieve membranes for nitrogen/methane separation, Georgia Institute of Technology, Ph.D. Dissertation, 2014

[34] H. Ku, Notes on the use of propagation of error formulas, J. Res. Natl. Bur. Stand., 70C (1966), pp. 263-273

[35] A.F. Ismail, K. Khulbe, T. Matsuura, Gas Separation Membranes: Polymeric and Inorganic, Springer International Publishing, Gewerbestrasse, C.H., 2015

[36] V. Majer, V. Svoboda, Enthalpies of vaporization of organic compounds: a critical review and data compilation, Blackwell Scientific Publications, Oxford, U.K., 1985

[37] A. Singh, W.J. Koros, Significance of entropic selectivity for advanced gas separation membranes, Ind. Eng. Chem. Res., 35 (1996), pp. 1231-1234

[38] A. Singh, W.J. Koros, Energetic and entropic contributions to mobility selectivity in glassy polymers for gas separation membranes, Ind. Eng. Chem. Res., 38 (1999), pp. 3647-3654

[39] J. Crank, G.A. Park, Diffusion in Polymers, Academic Press Inc., New York, U.S.A., 1968

[40] A. Singh, W.J. Koros, Air separation properties of flat sheet homogeneous pyrolytic carbon membranes, J. Membr. Sci., 174 (2000), pp. 177-188 
[41] S. Glasstone, K.J. Laidler, H. Eyring, The Theory of Rate Processes, 1st Ed. McGraw-Hill, New York, U.S.A., 1941

[42] M. Rungta, Carbon molecular sieve dense film membranes for ethylene/ethane separations, Georgia Institute of Technology, Ph.D. Dissertation, 2012

[43] N. Bighane, Novel silica membranes for high temperature gas separations, Georgia Institute of Technology, Master's Thesis, 2011

[44] W.J. Smothers, Application of Refractories: Ceramic Engineering and Science Proceedings, Vol 8. John Wiley \& Sons Inc., New York City, USA, 2008

[45] P.R. Dvornic, High temperature stability of polysiloxanes, In: B. Arkles, G. Larson, Silicon Compounds: Silanes and Silicones, 2nd Ed. Gelest Inc, Morrisville, U.S.A., 2008 pp. 441-454

[46] X. Ning, W.J. Koros, Carbon molecular sieve membranes derived from Matrimid polyimide for nitrogen/methane separation, Carbon, 66 (2013), pp. 511-522

[47] W.J. Koros, D.R. Paul, Design considerations for measurement of gas sorption in polymers by pressure decay, J. Polym. Sci. B., 14 (1976), pp. 1903-1907

[48] T.T. Moore, S. Damle, P.J. Williams, W.J. Koros, Characterization of low permeability separation membranes and barrier materials; design and operation considerations, J. Membr. Sci., 245 (2004), pp. 227-231

[49] D.G. Pye, H.H. Hoehn, M. Panar, Measurement of gas permeability of polymers. I: permeabilities in constant volume/variable pressure apparatus, J. Appl. Polym. Sci., 20 (1976), pp. 1921-1931

[50] D.G. Pye, H.H. Hoehn, M. Panar, Measurement of gas permeability of polymers. II: apparatus for determination of permeabilities of mixed gases and vapors, J. Appl. Polym. Sci., 20 (1976), pp. 287-301.

[51] C.A. Schneider, W.S. Rasband, K.W. Eliceiri, NIH Image to Image J: 25 years of image analysis, Nature Methods, 9 (2012), pp. 671-675

[52] L. J. Bellamy, The infr-red spectra of complex molecules, 3rd ed, Chapman and Hall, London, U.K., 1975

[53] K.M. Steel, W.J. Koros, Investigation of porosity of carbon materials and related effects on gas separation properties, Carbon, 41(2003), pp. 253-266.

[54] M. Rungta, L. Xu, W.J. Koros, Structure-performance characterization for carbon molecular sieve membranes using molecular scale gas probes, Carbon, 85 (2015), pp. 429- 442.

[55] S. Fu, E.S. Sanders, S.S. Kulkarni, G.B. Wenz, W.J. Koros, Temperature dependence of gas transport and sorption in carbon molecular sieve membranes derived from four 6FDA based polyimides: entropic selectivity evaluation, Carbon, 95 (2015), pp. 995-1006

[56] R.T. Yang, Gas Separation by Adsorption Processes, Butterworth, Boston, U.S.A., 1987 
[57] C. Lastoskie, K.E. Gubbins, N. Quirke, Pore size distribution analysis of microporous carbons: a density functional theory approach, J. Phys. Chem., 97 (1993), pp. 4786-4796 